\title{
On the Relative Sensitivity of a Tropical Deep Convective Storm to Changes in Environment and Cloud Microphysical Parameters
}

\author{
DEREK J. POSSELT \\ Jet Propulsion Laboratory, California Institute of Technology, Pasadena, California \\ FEI HE \\ University of California, Los Angeles, Los Angeles, California \\ JENNIFER BUKOWSKI \\ Colorado State University, Fort Collins, Colorado \\ JEFFREY S. REID \\ Naval Research Laboratory, Monterey, California
}

(Manuscript received 26 June 2018, in final form 10 March 2019)

\begin{abstract}
Monte Carlo and Morris screening techniques are used to examine the relative sensitivity of deep convective simulations to changes in initial conditions (IC) versus changes to microphysical parameters (MP). IC are perturbed using a set of empirical orthogonal function-principal component pairs obtained from a database of tropical soundings, while MP are perturbed consistent with their range of realistic values. Monte Carlo experiments provide a broad overview of parameter-output response, while Morris screening techniques identify the most significant influences on specific model output variables. Changes to MP produce a similar order-of-magnitude response in convective hydrologic cycle, dynamics, and latent heating as changes to IC. Changes in IC appear to have a larger effect on radiative fluxes than perturbations to MP. The distribution of low-level latent heating reveals that changes in MP have a larger influence on cold pool properties than changes to the environment. The dominant effects are produced by a subset of cloud MP and thermodynamic structure functions, indicating perturbation of a subset of the control factors may be used to produce most of the variability in a short-term convective-scale ensemble forecast. The most influential MP are the autoconversion threshold, the rain particle size distribution intercept, and the ice particle fall speed parameters. The most influential EOFs are those that correspond to variability in lower- to midtropospheric temperature and water vapor, as well as zonal low-level shear. The results have implications for both the understanding of what influences convective development and the design of ensemble-based prediction and data assimilation systems.
\end{abstract}

\section{Introduction}

Deep convective systems organize in a variety of different configurations according to the vertical wind shear, buoyancy profile, and aerosol content and chemistry (e.g., Weisman and Klemp 1982; Rotunno et al. 1988; Houze 2004; van den Heever et al. 2006). The convective thermodynamic and dynamic (e.g., shear) environment is known to strongly influence

Corresponding author: Derek J. Posselt, derek.posselt@ jpl.nasa.gov the development of moist convection (Stevens 2005; Sherwood 2010; Sherwood et al. 2010; de Rooy et al. 2013; Kim et al. 2014; Virman et al. 2018). These sensitivities have been examined from an observational perspective (Johnson and Lin 1997; Holloway and Neelin 2009, 2010; Tobin et al. 2012; Masunaga 2012, 2013; Kumar et al. 2014; Pereira de Oliveira and Oyama 2015; Bergemann and Jakob 2016; Hannah et al. 2016; Schiro et al. 2016; Yuan 2016; Chen et al. 2017; Stevens et al. 2017; Virman et al. 2018), as well as via the use of high-resolution numerical models (Crook 1996; Derbyshire et al. 2004; Mapes 2004; 
Raymond and Sessions 2007; Eitzen and Xu 2008; Wandishin et al. 2008; Kuang 2010; Tulich and Mapes 2010; Cui et al. 2011; Kirshbaum 2011; Hagos and Leung 2012; Böing et al. 2012a,b; Hohenegger and Stevens 2013; Sessions et al. 2015; Takemi 2015; HernandezDeckers and Sherwood 2016; Hannah 2017; Tsai and Wu 2017; Wang and Sobel 2017). Cloud microphysical processes have also been shown to exert a key influence on the evolution of deep convection (e.g., Fovell and Ogura 1989; Ferrier 1994; Walko et al. 1995; Ferrier et al. 1996; Meyers et al. 1997; Fovell and Tan 1998; Grabowski et al. 1999; Grabowski 2003; Posselt 2016; Grabowski and Morrison 2016). Microphysics experiments have been concerned with addressing model error or understanding the cloud environment and in-cloud dynamics (Tao et al. 1995; Walko et al. 1995; Meyers et al. 1997; Grabowski et al. 1999; Wu et al. 1999; Petch and Gray 2001; Grabowski 2003; Saleeby and Cotton 2004; Gilmore et al. 2004; van den Heever and Cotton 2004; Tao 2007). Most cloud system sensitivity experiments vary one or two parameters at a time, while holding all others constant. Such an analysis is limited, as it cannot account for 1) interactions between parameters, or 2) the fact that model sensitivity may differ for different combinations of control factors. In addition, previous studies have tended to focus on either the sensitivity of convection to changes in the environment, or to changes in cloud microphysical processes, but have generally not compared them. A quantitative study of uncertainty in the microphysical parameters and the convective environment is useful for understanding the response of deep convection to intrinsic and extrinsic changes, as well as for identifying factors that may be most productively used to produce variability in ensemble prediction systems.

In our previous study (Posselt et al. 2015) we considered microphysics-convection interaction from a probabilistic perspective, and sampled the probability distribution of a set of cloud microphysical parameters for a given set of model output states. This analysis yielded information on model sensitivity for $a$ given outcome, as defined by the model precipitation rate, liquid and ice water path, and outgoing longwave and shortwave radiative fluxes produced by a specific set of parameter values. It also explored whether column integral measurements place sufficient constraint on model parameters. Our study, and other recent analyses using ensemble (Tong and Xue 2008) and variational (Wang et al. 2013) data assimilation methods found that simultaneous estimation of multiple parameters is challenging, if not impossible, perhaps because interactions between parameters and the model state are nonlinear. In experiments that utilized a 1D cloud model, with no interaction between microphysics and the shear and thermodynamic environment, parameter-state functional relationships exhibited strong, and often nonmonotonic, nonlinearity (Posselt and Vukicevic 2010, hereafter PV10; Posselt and Bishop 2012, hereafter PB12; Posselt et al. 2014, hereafter PHB14). Results obtained from a 3D domain (Posselt 2016) indicate that the feedback to model environment and dynamics did not serve to fundamentally change the sensitivity of the model or the nonlinearity in the parameter-model output relationships.

In our previous research, we limited our analysis to the influence of changes in cloud microphysical parameters on the model state. We did not study the sensitivity of convection to changes in the environment due to lack (at the time) of suitable structure functions with which to realistically perturb the temperature, relative humidity, and wind profiles. We have recently conducted an empirical orthogonal function (EOF)/principal component (PC) analysis of 8 years of soundings from the region of the Maritime Continent (Bukowski et al. 2017). The structure functions obtained from our EOF$\mathrm{PC}$ analysis allow us to perturb the environment using a relatively small number of degrees of freedom, while maintaining consistency with observed modes of tropical variability. In this study, we extend our previous work by examining the relative sensitivity of simulated convection to changes in microphysics and the convective environment. Specifically, we address the following questions:

1) What is the relative sensitivity of convective dynamics, latent heating, water, and energy budgets to changes in cloud microphysical parameters versus changes in the convective environment?

2) Which specific factors exert the greatest control over convective development and outcomes? Is the model uniformly sensitive to changes in these parameters, or does sensitivity depend on the values of other parameters?

3) What are the implications of the sensitivity analysis for ensemble prediction and data assimilation, as well as for the types of measurements needed to constrain uncertainty in deep convective systems?

As in our earlier study, we utilize three-dimensional cloud-system-resolving numerical simulations of deep convection; however, as we are concerned more with sensitivity than parameter estimation, we conduct a multivariate sensitivity analysis, rather than a Bayesian experiment. We vary the same 10 cloud microphysical parameters as were perturbed in our earlier studies (PV10; PB12; PHB14; Posselt 2016) and perturb the model initial sounding using the first five EOFs for 
temperature, relative humidity, and the $u$ and $v$ components of the wind (Bukowski et al. 2017). As in our previous study, the model output variables of interest include spatially averaged precipitation rate, liquid and ice water path, and top-of-atmosphere upwelling longwave and shortwave radiative flux; as well as mean vertical profiles of vertical velocity and latent heat release. All output variables are also averaged over three time periods identified in the control simulation: developing, mature, and dissipating.

The remainder of this paper is organized as follows. Section 2 presents an overview of the simulation configuration and the ensemble analysis methodology. The influence of changes in control parameters on vertically integrated quantities and convective heating and dynamics is presented in section 3 , while the attribution of changes in specific output variables to changes in individual control factors is examined in section 4 . A brief discussion of the implications of our results for generation of ensembles and design of observing systems is presented in section 5, and a summary and a list of major conclusions is provided in section 6 .

\section{Simulation configuration and ensemble analysis methodology}

\section{a. Goddard Cumulus Ensemble model}

The NASA Goddard Cumulus Ensemble (GCE) model is a nonhydrostatic cloud-resolving model developed for the purpose of studying convective systems across a range of scales (Tao and Simpson 1993; Simpson and Tao 1993; Tao et al. 2003; Tao 2007; Tao et al. 2014). As microphysics and cloud-radiation interactions are key focuses of this study, we provide a brief overview of key components of the cloud and radiation parameterizations. For a more detailed description of the GCE model, we refer the reader to Tao and Simpson (1993) and Tao et al. (2003, 2014). While the GCE model can be run with a variety of cloud microphysical schemes, the most common and well documented is the singlemoment bulk scheme (Lin et al. 1983; Rutledge and Hobbs 1984; Tao et al. 2003; Lang et al. 2007; Zeng et al. 2008; Lang et al. 2011). The scheme assumes that small cloud droplets and pristine ice crystals are monodisperse, and that rain, snow, and graupel particles have an exponential size distribution. The number of rain, snow, and graupel particles of diameter $D$ can be written as

$$
N_{x}(D)=N_{0 x} \exp \left(-\lambda_{x} D\right),
$$

where $N_{0 x}$ is the particle size distribution (PSD) slope intercept and $\lambda_{x}$ is the slope:

$$
\lambda_{x}=\left(\frac{\pi \rho_{x} N_{0 x}}{\rho_{a} q_{x}}\right)^{1 / 4} .
$$

Here, $\rho_{x}$ is the rain, snow, or graupel density; $\rho_{a}$ is the air density; and $q_{x}$ represents the mass mixing ratio. These equations implicitly assume the particles are spherical, and the variety of different snow and graupel shapes is accounted for by specifying different coefficients and exponents in the fall speed-diameter relationship:

$$
V_{x}(D)=a_{x} D^{b_{x}}
$$

The specific values of the coefficient $a_{x}$ and exponent $b_{x}$ are set consistent with a specified ice particle shape, and the functional relationships between fall speed and diameter are derived from field measurements (e.g., Locatelli and Hobbs 1974; Mitchell 1996; Heymsfield et al. 2002). Shortwave and longwave radiative fluxes are computed using the Chou and Suarez (1999) and Chou et al. (2001) schemes, respectively. When the effective radius equation is integrated over particle sizes [Eq. (1) above and Eq. (24) in Tao and Simpson (1993)], the resulting equation is

$$
r_{\mathrm{eff}_{x}}=\frac{3}{\lambda_{x}}=\frac{3}{\left(\frac{\pi N_{0 x} \rho_{x}}{\rho_{a} q_{x}}\right)^{0.25}} .
$$

Inspection of Eqs. (1)-(4) reveals several cloud microphysical parameters that 1) affect the size distributions and fall speeds of hydrometeors, and 2) must be set to a fixed value in the model, but in reality may lie somewhere in a range of physically realizable values. Each of the parameters, through their effect on cloud microphysical processes and particle size distributions, have a potential effect on the cloud hydrologic and energy budget. For example, changes in fall speed parameters [Eq. (3)] affect hydrometeor sedimentation, which affects the surface precipitation rate. Changes to the particle density and the slope intercept of the particle size distribution have an effect on the distribution of particle sizes, influencing the collision/collection processes, as well as radiative transfer. We note that, while two-moment microphysical schemes are increasingly the norm in cloud-system-resolving and mesoscale models (and even in some general circulation models), we have chosen to examine the GCE single-moment scheme for consistency with our previous studies. While our results would certainly differ if we used a two-moment scheme, we have found in a recent study (Morales et al. 2018) that many of the sensitive parameters in the GCE's single-moment 
scheme are similar to sensitive parameters in a twomoment parameterization.

\section{b. 23 February 1999 deep convective storm}

The simulated deep convective system is based on a well-studied case of land-based tropical convection on 23 February 1999 (Cifelli et al. 2002; Rickenbach et al. 2002). While this case occurred over the Amazon on a specific date, the sounding is quite comparable to profiles in convective environments in other regions of the tropics, as verified via quantitative comparison versus the database of soundings described in section $2 \mathrm{c}$ below (not shown). To enable the generation of the large numbers of simulations required for our ensemble analysis, and for consistency with our previous study of cloud microphysical sensitivity (Posselt 2016), we use a model configuration with 2-km horizontal grid spacing and a small domain. We note that, while this grid spacing is too coarse to resolve shallow convection, or individual deep convective updrafts, it is consistent with the highestresolution mesoscale numerical simulations routinely run at numerical weather prediction centers [e.g., the HighResolution Rapid Refresh (HRRR) model (Benjamin et al. 2016) and the Met Office Unified model (Tang et al. 2013)]. The control simulation is initialized from an observed sounding taken at Rebio Jaru, Brazil (Silva Dias et al. 2002), at 1200 UTC (Fig. 1) and has been evaluated via comparison to a well-validated high-resolution (250-m horizontal grid spacing) simulation of the case [see Lang et al. (2011) for details]. Simulations are run with 72 vertical levels that stretch in depth from $14 \mathrm{~m}$ at the surface to $600 \mathrm{~m}$ in the lower stratosphere (Lang et al. 2007, 2011), and the model is provided with specified time-varying surface sensible and latent heat fluxes consistent with those observed during the day. The boundary conditions are periodic in both the $x$ and $y$ directions, and no grid translation is applied. Convection is initiated by providing the model with a $20 \mathrm{~km} \times 20 \mathrm{~km}$ subregion at the center of the domain, within which land surface sensible heat fluxes are enhanced relative to latent heat fluxes. The overall effect is consistent with a dry cleared field in the midst of a relatively wet forested environment (S. Lang 2015, personal communication). The coarse-resolution model is run on a $64 \mathrm{~km} \times 24 \mathrm{~km}$ horizontal domain, while the high-resolution model is run on a $64 \mathrm{~km} \times 64 \mathrm{~km}$ domain. We refer readers to our previous paper (Posselt 2016) for a detailed evaluation of the coarse-resolution case, and provide a brief comparison between coarse- and fine-resolution simulations here. We do not expect a relatively coarse-resolution simulation to replicate the output generated by a true cloud-resolving run (Bryan et al. 2003); rather, our purpose is to demonstrate the extent to which the

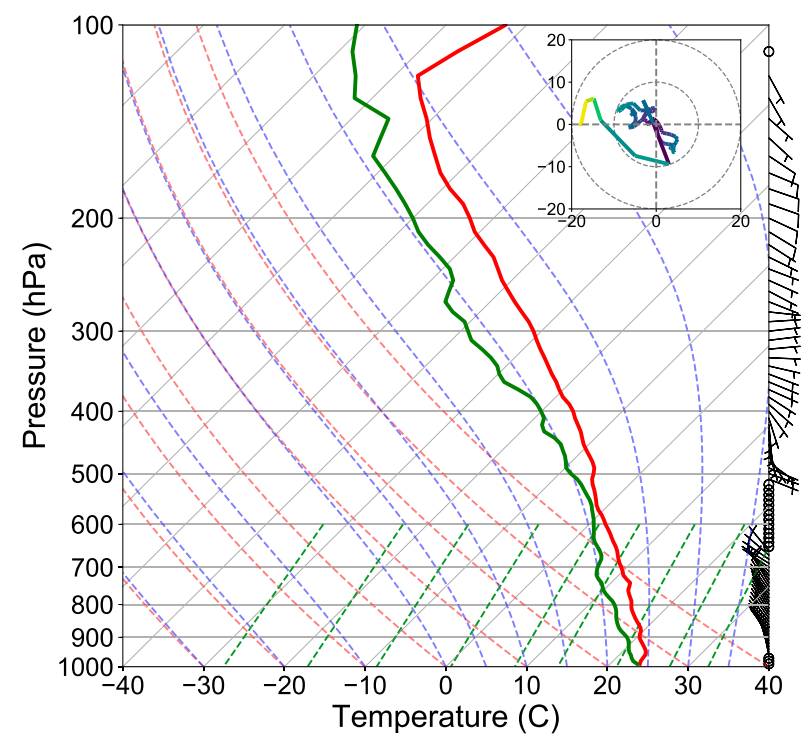

FIG. 1. Skew $T-\log p$ diagram for the default model sounding taken at 1200 UTC 23 Feb 1999 at Rebio Jaru, Brazil.

coarse-resolution run reproduces the general convective development in the high-resolution run.

The coarse- and high-resolution simulations produce similar spatial patterns of convective condensate and vertical motion (Fig. 2). Convection in each run develops over the upshear boundary of the region of surface heating (Figs. 2a,d). The time it takes for convection to develop is similar, with systems maturing after approximately 275 simulated minutes (Figs. 2b,e), then beginning to dissipate by approximately $320 \mathrm{~min}$ (Figs. 2c,f). Posselt (2016) compared coarse- and fine-resolution simulations, examining time series of domain-mean vertically integrated hydrologic quantities and radiative fluxes and the temporally and spatially averaged profiles of vertical velocity and cloud mass mixing ratio. The cloud liquid and ice vertical distributions were very similar for the two simulations, as was the temporal evolution of the radiative fluxes and the liquid and ice water path.

\section{c. Generation of ensembles and quantities of interest}

The fundamental goal of this study is to examine the relative sensitivity of convective outcomes to changes in 1) a set of cloud microphysical parameters, and 2) the convective environment. In so doing, we conduct ensemble experiments in which we first randomly vary the control factors, and then systematically explore the sensitivity of each output variable to each input factor. The randomly generated (Monte Carlo) ensemble provides information on the distribution of model outcomes associated with variations in control factors, and the use of a large ensemble reduces the sampling error. 
Cloud and W, $220 \mathrm{~min}$

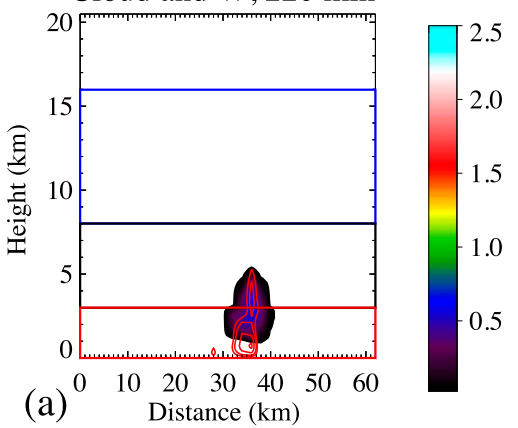

Cloud and W, $250 \mathrm{~m} 220 \mathrm{~min}$

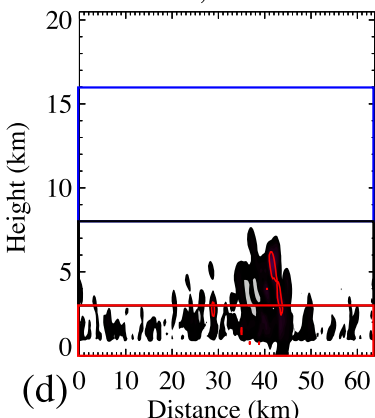

Cloud and W, 275 min

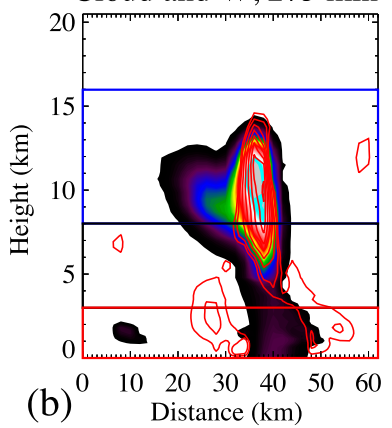

Cloud and W, $250 \mathrm{~m} 275 \mathrm{~min}$

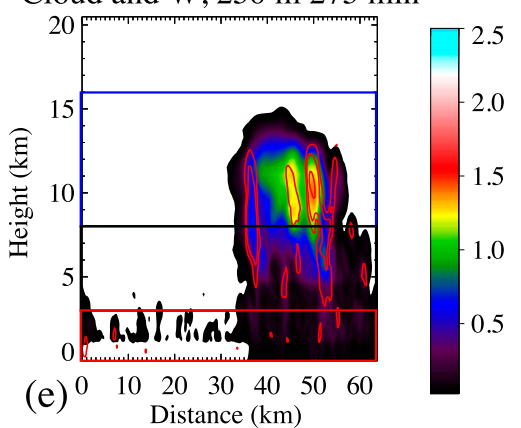

Cloud and W, 320 min

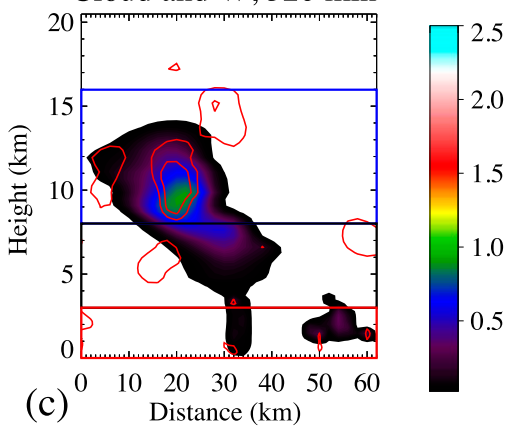

Cloud and W, $250 \mathrm{~m} 320 \mathrm{~min}$

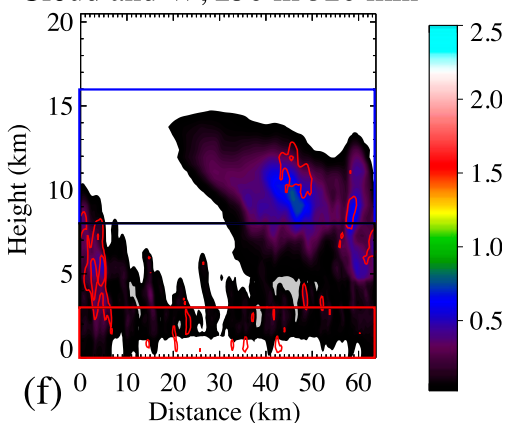

FIG. 2. Time-height cross sections of total condensate mixing ratio $\left(\mathrm{g} \mathrm{kg}^{-1}\right.$; color-filled contours) and upward vertical velocity (every $0.5 \mathrm{~m} \mathrm{~s}^{-1}$ starting at $0.5 \mathrm{~m} \mathrm{~s}^{-1}$; red contours) for (a),(d) developing, (b),(e) mature, and (c),(f) dissipating times in the storm life cycle. Output from the 2-km-horizontal-grid control simulation is shown in (a)-(c) while output from the high-resolution (250-m grid spacing) reference simulation is depicted in (d)-(f). The boxes correspond to low (red), middle (black), and high (blue) averaging regions (see text for details).

The smaller subset of systematic variations facilitates identification of the factors that exert the largest degree of control over each output variable at each model output time.

Ten cloud microphysical parameters are used as control variables in the microphysics perturbation experiments (Table 1), and their ranges of variability are derived from measurements of raindrop PSD (Tokay and Short 1996; Roy et al. 2005) and ice crystal particle size distribution and particle shape (Locatelli and Hobbs 1974; Mitchell 1996; Heymsfield et al. 2002). Parameter values in the control simulation are similar to those used in single-moment bulk cloud microphysical schemes in current cloud-resolving and mesoscale models (Table 1),

TABLE 1. Cloud microphysical parameters perturbed in the Monte Carlo and MOAT experiments, along with default values and parameter ranges. Note that we have reported all values in CGS units to be consistent with what is used in the model formulation.

\begin{tabular}{|c|c|c|c|c|c|}
\hline Parameter description & Variable & Units & Default & Min & Max \\
\hline Snow fall speed coefficient & $a_{s}$ & $\mathrm{~cm}^{1-b_{s}}$ & 200 & 50 & 1000 \\
\hline Snow fall speed exponent & $b_{s}$ & - & 0.3 & 0.1 & 1 \\
\hline Graupel fall speed coefficient & $a_{g}$ & $\mathrm{~cm}^{1-b_{g}}$ & 400 & 50 & 1200 \\
\hline Graupel fall speed exponent & $\dot{b_{g}}$ & - & 0.4 & 0.1 & 0.9 \\
\hline $\begin{array}{l}\text { Threshold cloud mass mixing ratio } \\
\text { for autoconversion to rain }\end{array}$ & $q_{c 0}$ & $\mathrm{~g} \mathrm{~kg}^{-1}$ & 1 & 0.1 & 3 \\
\hline $\begin{array}{l}\text { Slope intercept of the rain particle size } \\
\text { distribution }\end{array}$ & $N_{0 r}$ & $\mathrm{~cm}^{-4}$ & 0.5 & 0.01 & 5 \\
\hline $\begin{array}{l}\text { Slope intercept of the snow particle size } \\
\text { distribution }\end{array}$ & $N_{0 s}$ & $\mathrm{~cm}^{-4}$ & 0.5 & 0.01 & 5 \\
\hline $\begin{array}{l}\text { Slope intercept of the graupel particle size } \\
\text { distribution }\end{array}$ & $N_{0 g}$ & $\mathrm{~cm}^{-4}$ & 0.5 & 0.01 & 5 \\
\hline Snow particle density & $\rho_{s}$ & $\mathrm{~g} \mathrm{~cm}^{-3}$ & 0.2 & 0.05 & 0.5 \\
\hline Graupel particle density & $\rho_{g}$ & $\mathrm{~g} \mathrm{~cm}^{-3}$ & 0.4 & 0.2 & 0.9 \\
\hline
\end{tabular}


and output from the control case (Table 2) is generated by running a 5.5 -h integration of the model using the default set of parameters and an unperturbed sounding. A 10000-member ensemble of GCE simulations with perturbed microphysics is generated via random draws of 10000 sets of microphysical parameter values. As in our previous work, we assume that the parameters may take any value over the ranges specified in Table 1 with equal probability. This corresponds to a uniform distribution with bounds set to the parameter minimum and maximum value. We use a noninformative prior distribution to be consistent with our previous experiments. In contrast to our previous studies, we apply additional restrictions on snow and graupel parameters, requiring $a_{s}<a_{g}$ (graupel falls faster than snow) and $\rho_{s}<\rho_{g}$ (graupel is denser than snow). We have also adjusted the range of snow and graupel densities to be more consistent with what we expect real clouds to produce. Note that the default values are not equal to the midpoint of the range, meaning that perturbed parameter sets will not be distributed evenly around the control set. In all simulations with perturbed microphysics, the model initial conditions are set equal to the default sounding shown in Fig. 1.

Model-based analysis of the response of convective systems to changes in the environment requires perturbation of the vertical thermodynamic structure (e.g., temperature and water vapor content), as well as the $u$ and $v$ components of the wind. Let us assume that soundings of temperature $T$, relative humidity $(\mathrm{RH})$, zonal wind $u$, and meridional wind $v$ are available on $25-\mathrm{hPa}$ levels from the surface $(1000 \mathrm{hPa})$ to the lower stratosphere $(50 \mathrm{hPa})$. In a brute force sensitivity analysis, each variable would be perturbed at each level independently. In the simplest case, each variable at each level could be perturbed just once, independent of the others. This equates to $(4 \text { variables } \times 39 \text { layers })^{2}=$ 24336 simulations. If we wish to explore a range of values for each thermodynamic and wind variable at each level, the analysis requires (4 variables $\times 39$ layers) ${ }^{N}$, where $N$ is the number of discrete values of each variable to be examined at each level. There are both practical and theoretical problems with this type of analysis. First, it is computationally unfeasible, as even $N=3$ translates to more than 3 million model integrations. It is also not physically realistic, as the atmosphere exhibits patterns of variability that are vertically correlated. Bukowski et al. (2017) conducted an EOF-PC analysis, a statistical method employed to quantify independent structures of variability, on a database of soundings taken at three sites in the Maritime Continent during the period $2008-16$. They found that $80 \%$ of the variance in the sounding database could be explained by
TABLE 2. Model output quantities of interest used in parameter sensitivity experiments.

\begin{tabular}{ll}
\hline \multicolumn{1}{c}{ Output quantity } & \multicolumn{1}{c}{ Units } \\
\hline Precipitation rate & $\mathrm{mm} \mathrm{h}^{-1}$ \\
Liquid water path & $\mathrm{mm}$ \\
Ice water path & $\mathrm{mm}$ \\
TOA LW radiative flux & $\mathrm{W} \mathrm{m}^{-2}$ \\
TOA SW radiative flux & $\mathrm{W} \mathrm{m}^{-2}$ \\
Upward vertical velocity & $\mathrm{m} \mathrm{s}^{-1}$ \\
Latent heat release & $\mathrm{K} \mathrm{day}^{-1}$ \\
\hline
\end{tabular}

the first 5 EOFs of temperature, relative humidity, $u$, and $v$. Use of a set of 20 EOFs allows us to reduce the dimensionality of the problem considerably, and 1) makes it tractable to produce a large ensemble of input initial conditions, and 2) ensures that the perturbations are consistent with observed modes of tropical variability. While it is well known that the thermodynamic (and to a lesser extent dynamic) variables are correlated, we chose intentionally to neglect correlations among the sounding variables to facilitate attribution of changes in model output to perturbations to specific sounding variables.

Perturbed model initial conditions are produced by multiplying the first 5 standardized and nonrotated EOFs for $T, \mathrm{RH}, u$, and $v$ (Fig. 3) by 20 independently drawn normally distributed random numbers, with mean of zero and standard deviation equal to current uncertainty estimates for radiosonde vertical profiles (e.g., Rienecker et al. 2008; Table 3). The resulting perturbations are then added to the control sounding, and the resulting profile is used to initialize the GCE model. Three sets of 3330 soundings (for a total of 9990 profiles) are generated using perturbations obtained from Singapore, Riau Island (Ranai) in the southern South China Sea, and Puerto Princesa on Palawan Island in the Philippines. Bukowski et al. (2017) showed that these three sites exhibited similar behavior, but with local variations due in part to the proximity to larger landmasses and topography. As an indication of the resulting variability in the thermodynamic profile produced by relative small perturbations to the initial conditions, we compute and plot the convective available potential energy (CAPE; Fig. 4a) and convective inhibition (CIN; Fig. 4b) for the set of 9990 soundings. Perturbations to the initial profile result in values of CAPE that range from 200 to $1800 \mathrm{~J} \mathrm{~kg}^{-1}$, and values of CIN that range from 0 to $100 \mathrm{~J} \mathrm{~kg}^{-1}$. Note that CAPE is computed using a 500-m-deep mixed layer, with no assumed water loading, and saturation with respect to liquid at temperatures above freezing, ice at temperatures less than $-40^{\circ} \mathrm{C}$, and a weighted mean of liquid and ice between $-40^{\circ}$ and $0^{\circ} \mathrm{C}$. The CAPE and CIN of the 


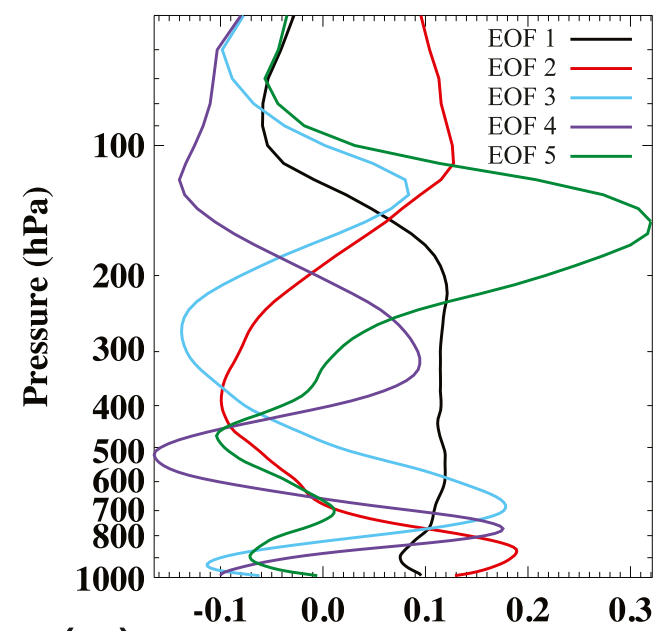

(a) Standardized Temperature EOF

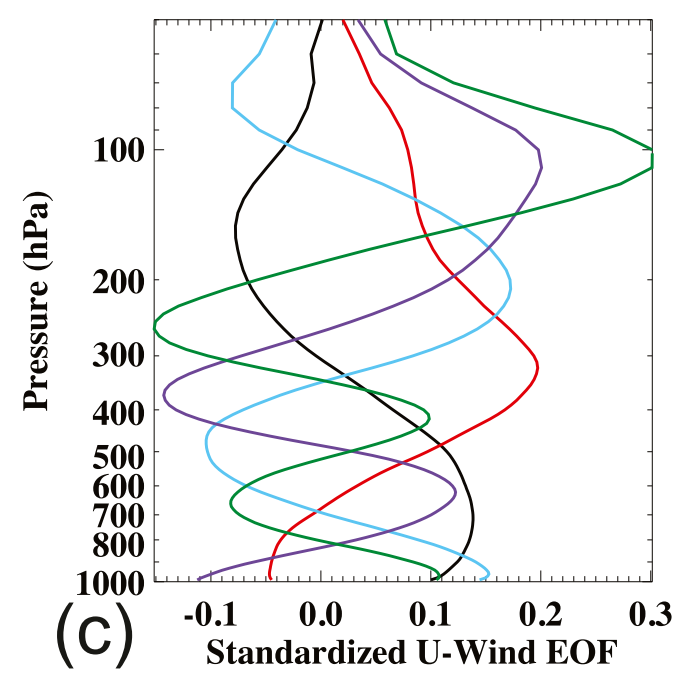

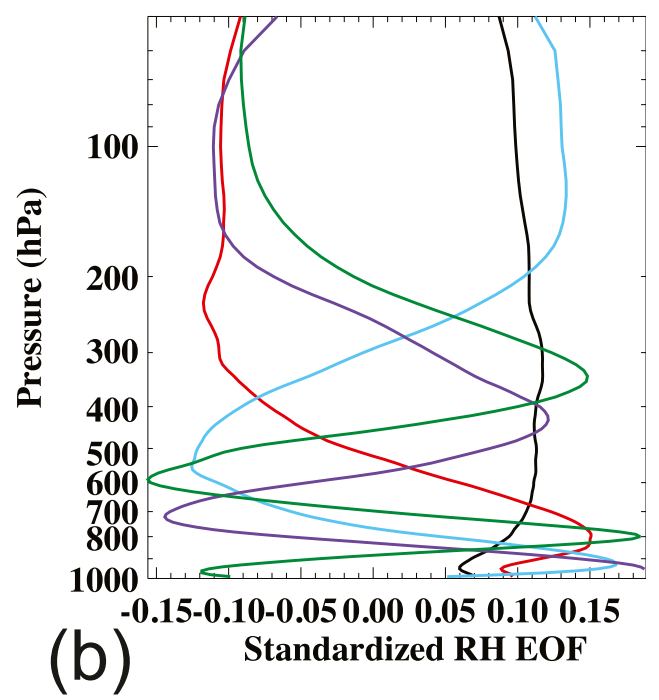

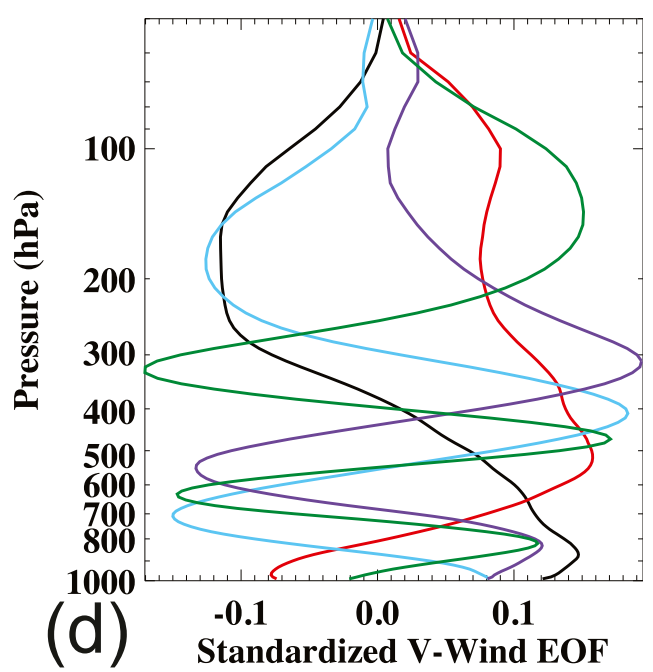

FIG. 3. Plots of the first five vertical-structure functions (i.e., EOFs) of (a) temperature, (b) relative humidity, (c) zonal wind, and (d) meridional wind.

control sounding are 1028.6 and $21.7 \mathrm{~J} \mathrm{~kg}^{-1}$, respectively. The 800-hPa-surface difference in wind speed in the control sounding is $6.1 \mathrm{~m} \mathrm{~s}^{-1}$, and perturbations to the $u$ - and $v$-direction winds result in changes in this difference of less than $\pm 0.5 \mathrm{~m} \mathrm{~s}^{-1}$.

As in Posselt (2016), we examine quantities analogous to those commonly retrieved from modern satellite systems (e.g., TRMM, GPM, and A-Train), including precipitation rate (PCP), liquid water path (LWP), ice water path (IWP), and top of atmosphere longwave and shortwave broadband radiative flux [outgoing longwave radiation (OLR) and outgoing shortwave radiation (OSR)]. To make the analysis of large ensembles of model simulations tractable, we average the PCP, LWP, IWP, OLR, and OSR over the model domain, and over time periods corresponding to convective development (180-230 min), maturity (230-280 min), and dissipation (280-330 min). We also output the domain-mean vertical profiles of upward and downward vertical velocity (averaged only over model grid points where vertical velocity is positive and negative, respectively) and latent

TABLE 3. Standard deviation of the perturbations to EOFs of each initial-sounding variable.

\begin{tabular}{lc}
\hline \hline Sounding variable & Standard deviation \\
\hline Temperature & $1 \mathrm{~K}$ \\
Relative humidity & $10 \%$ \\
$u$-direction wind & $1 \mathrm{~m} \mathrm{~s}^{-1}$ \\
$v$-direction wind & $1 \mathrm{~m} \mathrm{~s}^{-1}$ \\
\hline
\end{tabular}



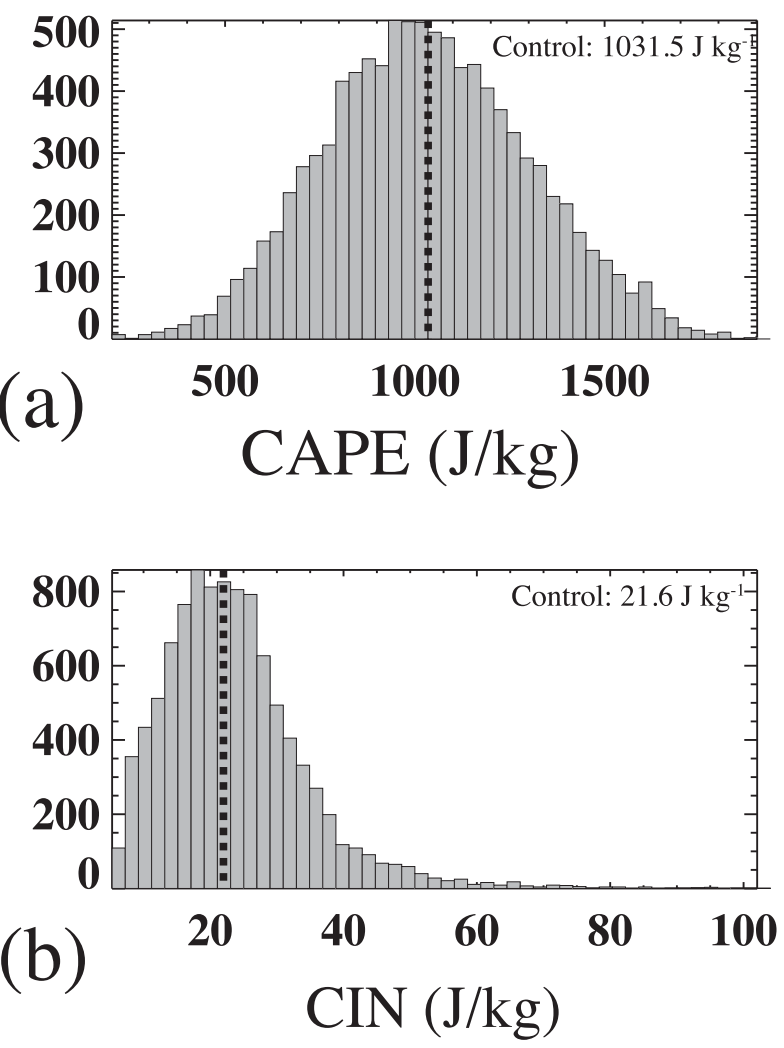

FIG. 4. Histograms of (a) convective available potential energy (CAPE; $\mathrm{J} \mathrm{kg}^{-1}$ ) and (b) convective inhibition (CIN; $\mathrm{J} \mathrm{kg}^{-1}$ ) for the ensemble of profiles generated via perturbations on the model initial sounding. CAPE and CIN values for the control sounding are listed in each panel and depicted with a vertical dashed line.

heat release, averaged over the same three time periods. Note that, when the initial sounding is perturbed, the development time scale for convection will almost certainly change. We acknowledge that simulations with different initial soundings may not produce output that falls neatly into the three time periods we refer to as "developing," "mature," or "dissipating." For ease of comparison, we maintain consistent averaging over the same model output time intervals and, where appropriate, note that these times may not always correspond (internally) to the same stages of development.

For compactness, and consistency with our previous analysis, we also average the vertical profile variables over three layers: low $(0-3.5 \mathrm{~km})$, middle $(3.5-8 \mathrm{~km})$, and high $(8-16 \mathrm{~km})$. In summary, the microphysics and initial condition perturbation experiments each yield the same set of output quantities of interest: PCP, LWP, IWP, OLR, and OSR averaged over the model domain and over three time periods; and upward vertical motion $W+$ and enthalpy of phase change [latent heat release (LHR)] averaged over the model domain, three convective time periods, and three broad vertical layers. The result is
33 distinct output variables: ( 5 column variables $\times$ 3 times $)+(2$ profile variables $\times 3$ layers $\times 3$ times $)$. In the examination and discussion of results that follow, we refer to the microphysics perturbation experiments with the designation MP, and to the perturbations in initial conditions as IC.

\section{Ensemble analysis}

\section{a. Bulk hydrologic and radiative variables}

We begin with an analysis of vertically integrated hydrologic (precipitation and liquid and ice water path) and radiative (outgoing longwave and shortwave fluxes) variables at each of the three convective time periods (Table 4). Histograms of these variables indicate the relative effect of changes in microphysics versus initial conditions on model output. As shown in Posselt's (2016) study of cloud microphysical sensitivity, changes in cloud microphysical variables have little effect on model output early in convective development (Figs. 5a-e). This is consistent with the fact that it is primarily condensation (and eventually collisioncoalescence) that is active in the early phase. Changes in the model sounding have somewhat larger effect on the model liquid water path and outgoing shortwave radiation (Figs. 5b, and 5e, respectively). This likely reflects the influence of changes in static stability on the timing and strength of convection, and the resulting changes in liquid water and consequences for reflected shortwave radiation. During the mature phase of development (Figs. 5f-j), changes to microphysics and sounding characteristics produce very similar dispersion in the modeled precipitation rate and liquid water path, while changes to the sounding produce much larger dispersion in the ice water path and radiative fluxes. Changes in microphysics produce a broad range of precipitation rates and IWP (Figs. $5 \mathrm{f}, \mathrm{h}$ ), but the domainand time-averaged precipitation is always larger than $0.2 \mathrm{~mm} \mathrm{~h}^{-1}$ and there is always a nonzero amount of ice. In contrast, changes in the model sounding may produce a complete cessation in rainfall and zero IWP. Simulations with zero IWP are likely those that have not yet developed to maturity. While perturbations in MP and IC produce a similar range of LWP, the distributions are skewed in opposite directions. Changes in microphysics generally lead to larger LWP, while changes in the initial sounding produce generally smaller LWP.

At later times in each simulation (Figs. 5k-o), MP and IC produce similar distributions of precipitation rate (mean, dispersion, and skewness). Mean precipitation rates are lower for both MP and IC at this time (Fig. 5k) than in the mature phase (Fig. 5f), indicating changes in 
TABLE 4. Standard deviation of the ensemble of column-integral quantities generated from randomly drawn parameter and initialcondition values in each of the three time intervals.

\begin{tabular}{|c|c|c|c|c|c|}
\hline & Precipitation rate $\left(\mathrm{mm} \mathrm{h}^{-1}\right)$ & $\operatorname{LWP}\left(\mathrm{kg} \mathrm{m}^{-2}\right)$ & $\operatorname{IWP}\left(\mathrm{kg} \mathrm{m}^{-2}\right)$ & $\operatorname{OLR}\left(\mathrm{W} \mathrm{m}^{-2}\right)$ & $\operatorname{OSR}\left(\mathrm{W} \mathrm{m}^{-2}\right)$ \\
\hline \multicolumn{6}{|l|}{ Microphysics } \\
\hline Developing & $1.26 \times 10^{-2}$ & $3.68 \times 10^{-3}$ & $2.19 \times 10^{-3}$ & $7.18 \times 10^{-2}$ & 1.28 \\
\hline Mature & 0.22 & $5.43 \times 10^{-2}$ & 0.14 & 4.61 & 15.66 \\
\hline Dissipating & 0.09 & 0.14 & 0.24 & 6.15 & 27.35 \\
\hline \multicolumn{6}{|c|}{ Initial conditions } \\
\hline Developing & $4.15 \times 10^{-2}$ & $3.88 \times 10^{-2}$ & $2.19 \times 10^{-2}$ & 0.84 & 5.65 \\
\hline Mature & 0.16 & 0.05 & 0.31 & 13.50 & 42.76 \\
\hline Dissipating & 0.10 & 0.07 & 0.18 & 21.54 & 68.84 \\
\hline
\end{tabular}

MP and IC did not systematically delay development to later times. As in the previous phase of development, changes in microphysical parameters result in generally larger liquid and ice water path, as well as a larger LWP and IWP variance, relative to changes in the initial sounding. In contrast to earlier times, there are no combinations of MP or IC that result in zero LWP or IWP. The implication is that some form of cloud will develop in this case, and of the cloud systems that form, the vast majority produce nonnegligible ice content, indicating vertical development above the melting level. The relatively large variance in the distributions of OLR and OSR that is produced by changes in IC appears to reflect a spectrum of cloud depths, as the OLR ranges from values that are indicative of very low clouds $\left(>270 \mathrm{~W} \mathrm{~m}^{-2}\right)$ to values that are indicative of high thick clouds $\left(<200 \mathrm{~W} \mathrm{~m}^{-2}\right)$. The relatively narrow distribution of liquid water path for IC, relative to ice water path, indicates much of the variability in the radiative fluxes derives from changes in ice rather than liquid.

Considering all distributions presented in Fig. 5, it is interesting that the maxima in the MP distributions are commonly shifted with respect to the default. It is possible that this is because the default values do not lie at the center of the range of variability for MP, while IC perturbations are symmetric around the default sounding. However, even when the ensemble is subset to include parameter values that are evenly dispersed around the default values (not shown), the resulting distributions of output variables are often still not centered on

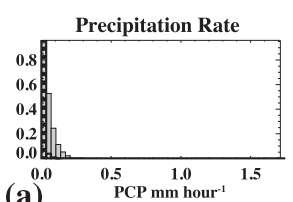

(a)

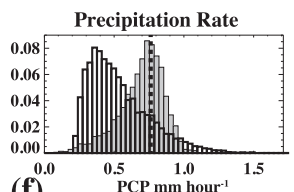

(f)

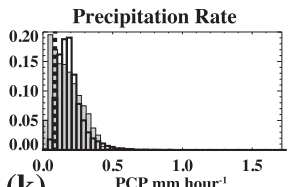

(k)

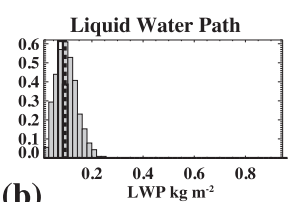

(b)

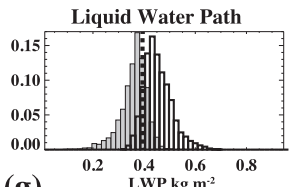

(g)

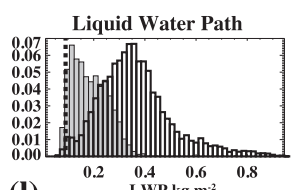

(l)

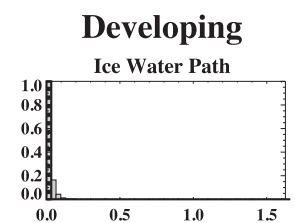

(c)

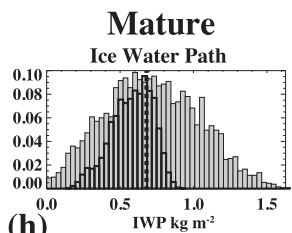

(h)

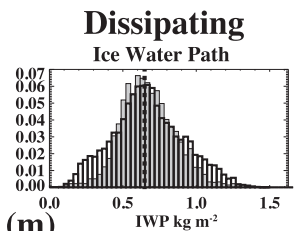

(m)

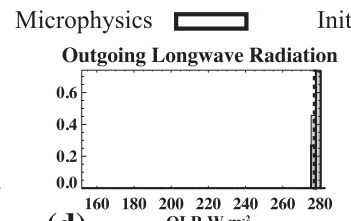

(d)

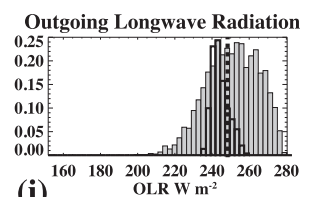

(i)

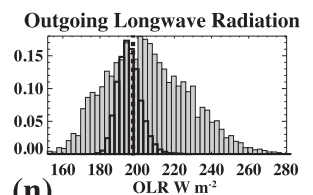

(n)

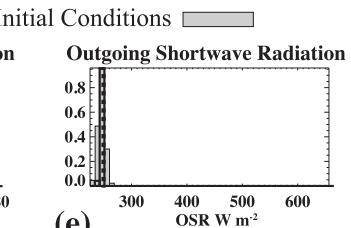

(e)
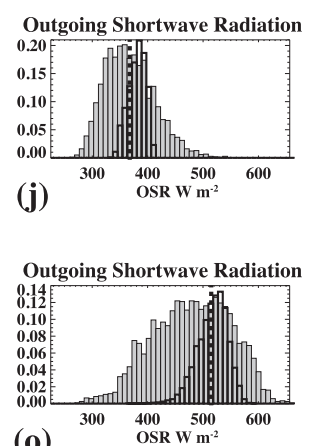

(o)

FIG. 5. Histograms (normalized to a sum of 1.0) of GCE output (a),(f),(k) precipitation rate $\left(\mathrm{mm} \mathrm{h}^{-1}\right)$, (b),(g),(l) liquid water path $\left(\mathrm{kg} \mathrm{m}^{-2}\right),(\mathrm{c}),(\mathrm{h}),(\mathrm{m})$ ice water path $\left(\mathrm{kg} \mathrm{m}^{-2}\right)$, and top of atmosphere upwelling (d),(i),(n) longwave and (e),(j),(o) shortwave radiative flux $\left(\mathrm{W} \mathrm{m}^{-2}\right.$ ) for (a)-(e) developing, (f)-(j) mature, and (k)-(o) dissipating times. Unfilled boxes correspond to the ensemble generated from perturbations on microphysical parameters, while gray-filled boxes correspond to the ensemble generated from perturbations on the model initial conditions. Black dashed vertical lines mark the position of the output from the control simulation for each variable and each time. 


\section{Initial Conditions}

Developing, Level 3

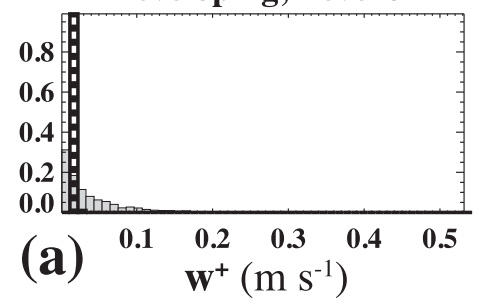

Developing, Level 2
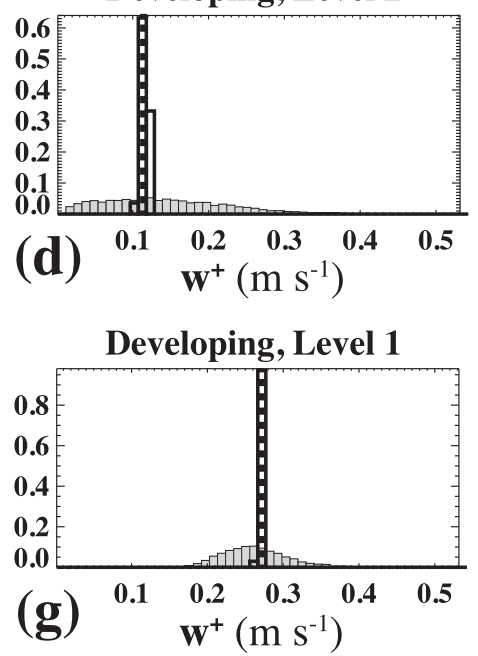

Microphysics
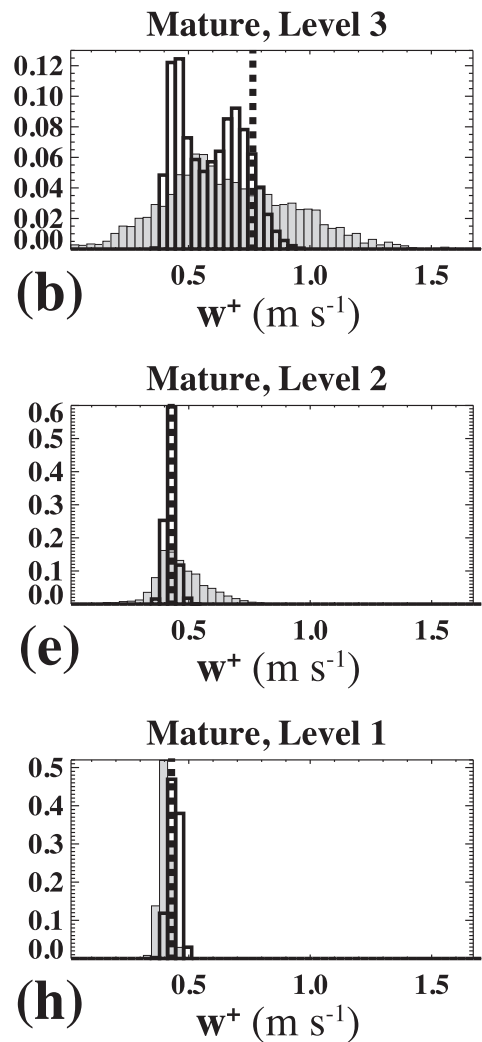

Dissipating, Level 3

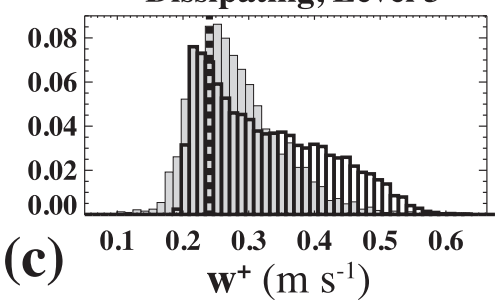

Dissipating, Level 2

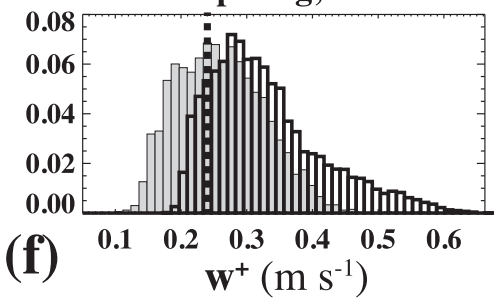

Dissipating, Level 1

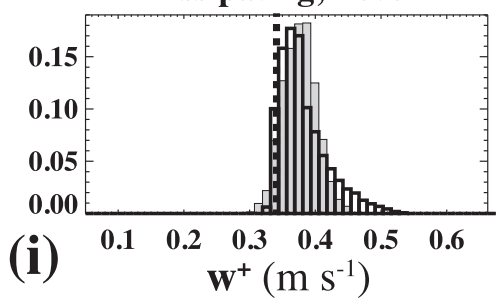

FIG. 6. Histograms (normalized to a sum of 1.0) of GCE output upward vertical velocity ( $\mathrm{m} \mathrm{s}^{-1}$ ) for (a),(d),(g) developing, (b),(e),(h) mature, and (c),(f),(i) dissipating times for the (a)-(c) upper, (d)-(f) middle, and (g)-(i) lower layers. Boxes and dashed vertical lines are as in Fig. 5.

the default output values. This reflects nonlinearity in the relationships between control factors and model responses. Nonlinearity in the parameter-response relationship has been discussed in many of our previous papers, and skewness in the IC PDFs indicates nonlinearity in the response to changes in IC as well. Nonlinearity does not appear to be a function of time, as distribution means are just as likely to be offset from the control values in the mature phase as they are in the dissipating phase.

\section{b. Convective vertical velocity and heating}

We assess the effect of changes in MP and IC on convective heating and dynamics by examining distributions of mean upward vertical velocity (Fig. 6) and latent heating/cooling (Fig. 7). In addition to examining developing, mature, and dissipating phases, we also divide the model output into three broad layers corresponding to liquid only (layer $1 ; 0-3.5 \mathrm{~km}$ ), mixed phase (layer $2 ; 3.5-8 \mathrm{~km}$ ), and ice only (layer $3 ; 8-16 \mathrm{~km}$ ). Mean upward vertical velocity is computed by averaging over only those grid points with vertical motion greater than $0.0 \mathrm{~m} \mathrm{~s}^{-1}$. As with the distributions of precipitation, water path, and radiative fluxes, changes in cloud microphysical parameters have little effect on the mean vertical velocity early in the cloud development (Figs. 6a,d,g). In contrast, changes in IC lead to changes in updraft speeds with an order of magnitude more variability than do changes to MP (Table 5). There is little overlap between the updraft speeds at the developing times and those in the mature phase; vertical velocities are systematically higher in the middle phase of the simulation. Relative to the vertical velocity at lower and middle levels (Figs. 6h,e), changes in MP and in IC both have a large effect on vertical velocities in the upper troposphere. Changes in both MP and IC produce a relatively large range of model solutions, though the response to IC is approximately twice the response to MP (Table 5). There is a lower bound to the upward vertical velocity produced by changes to MPall simulations exhibit mean upward vertical motion greater than approximately $0.4 \mathrm{~m} \mathrm{~s}^{-1}$. In contrast, changes in the initial sounding are capable of producing simulations with very weak ascending motion in the 


\section{Initial Conditions}

Developing, Level 3

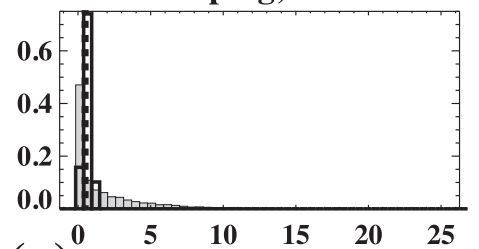

(a) $\operatorname{LHR}\left(\mathrm{K} \mathrm{day}^{-1}\right)$

Developing, Level 2

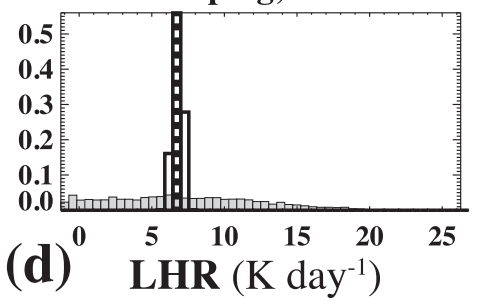

Developing, Level 1

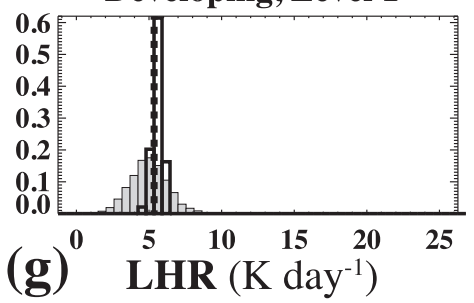

Microphysics

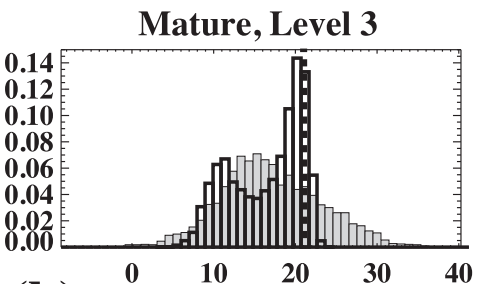

(b) $\operatorname{LHR}\left(\mathrm{K} \mathrm{day}^{-1}\right)$

Mature, Level 2

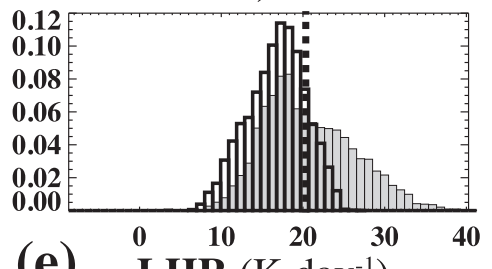

(e) $\operatorname{LHR}\left(\mathrm{K} \mathrm{day}^{-1}\right)$

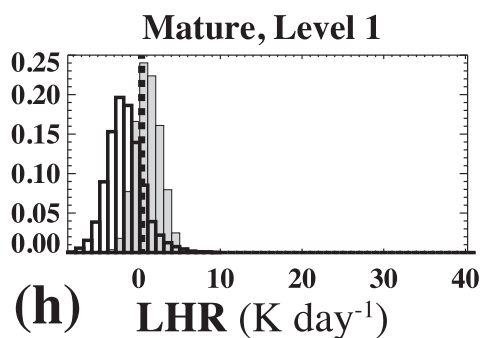

Dissipating, Level 3

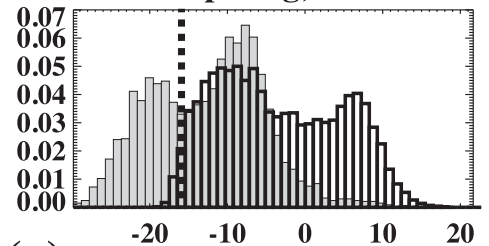

(c) $\quad \mathbf{L H R}\left(\mathrm{K} \mathrm{day}^{-1}\right)$

Dissipating, Level 2

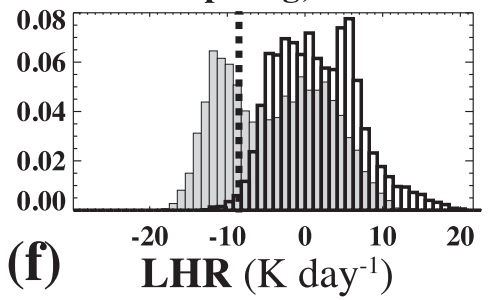

Dissipating, Level 1

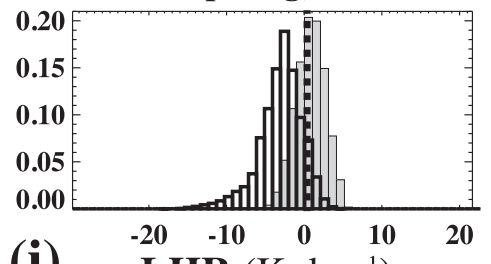

FIG. 7. As in Fig. 6, but for latent release $\left(\mathrm{K} \mathrm{day}^{-1}\right)$.

upper troposphere. Examination of subsets of the MC ensemble indicate the peak in the PDF of updrafts centered around $\sim 0.5 \mathrm{~m} \mathrm{~s}^{-1}$ is associated with large fall velocities of snow and graupel ( $a_{s}$ and $a_{g}>$ default). In the dissipating phase (Figs. 6c,f,i) updraft PDFs have considerable skewness at all levels. Changes in MP and IC produce similar variability in the updraft spectrum, with MP exerting slightly more influence (more variance in the ensemble; Table 5), and producing on average larger updraft speeds. Skewness in the MP updraft distribution is due, in part, to large snow and graupel fall speeds; upward vertical velocity values greater than $0.4 \mathrm{~m} \mathrm{~s}^{-1}$ are entirely associated with large values of $a_{s}$ and $a_{g}$. Increases in ice hydrometeor fall speeds first inhibit updrafts in the mature phase, then enhance them later. Skewness in the distribution of updrafts produced by IC is interesting, and may be due to the fact that changes to the default sounding produce CAPE values generally greater than $500 \mathrm{~J} \mathrm{~kg}^{-1}$ (Fig. 4a).

Distributions of latent heat release are generally consistent with the distributions of vertical velocity during the development phase (Figs. 7a,d,g), with MP producing small changes and IC producing a broader range of values. Simulations nearly uniformly produce positive values of LHR in the early phase, with just a few ensemble members producing negative latent heat $(\mathrm{LH})$ values at midlevels. At maturity, there is a broad spectrum of LH values at all levels with the largest range seen in the middle and upper troposphere. At low levels (Fig. 7h), changes to IC and to MP are capable of producing either net warming or cooling, but changes to MP are more likely to lead to cooling than IC. This indicates MP has a stronger effect on the development and properties of cold pools than does IC. At midlevels

TABLE 5. Standard deviation of the ensemble of mean upward vertical velocities $\left(\mathrm{cm} \mathrm{s}^{-1}\right)$ generated from randomly drawn parameter and initial-condition values in each of the three time intervals.

\begin{tabular}{lcrc}
\hline \hline & Developing & Mature & Dissipating \\
\hline Microphysics & & & \\
$\quad$ Upper & 0.17 & 13.14 & 9.17 \\
Middle & 0.45 & 2.19 & 8.57 \\
Low & 0.12 & 2.15 & 3.63 \\
Initial conditions & & & \\
$\quad$ Upper & 4.29 & 25.77 & 6.64 \\
Middle & 8.02 & 10.40 & 6.59 \\
Low & 3.92 & 2.23 & 2.53 \\
\hline
\end{tabular}


(Fig. 7e), LH is uniformly positive for all MP and IC members, with values ranging over a large range $\left(15-30 \mathrm{~K} \mathrm{day}^{-1}\right)$. As at lower levels, changes in MP are more likely to reduce the heating, while the mean of the distribution of LHR is approximately equal to the default value for the spectrum of perturbations to the IC. In contrast to low levels, IC produces a larger range of values at midlevels than does MP (Table 6). In the upper troposphere (Fig. 7b), LHR is uniformly positive, and the IC produces a larger range of outcomes than does the MP. Subsets of the ensemble of MP indicate most of the strongest cooling at low levels, along with the peak in LHR at $\sim 11 \mathrm{Kday}^{-1}$ is associated with large values of $a_{s}$ and $a_{g}$. In the dissipating phase, there is a very large range of possible LHR values produced by both MP and IC. At low levels (Fig. 7i), changes in MP primarily lead to increased cooling, with a relatively small number of members exhibiting net warming. Changes in the initial conditions produce a symmetric distribution of LHR at low levels, with cooling and warming equally likely. At midlevels, MP produces a nearly symmetric distribution of $\mathrm{LH}$ around $0 \mathrm{~K} \mathrm{day}^{-1}$, with values ranging from strongly cooling $\left(-10 \mathrm{~K} \mathrm{day}^{-1}\right)$ to strongly warming $\left(+20 \mathrm{~K} \mathrm{day}^{-1}\right)$. In contrast, changes to IC lead to a relatively larger number of simulations that exhibit net cooling than net warming. It is notable that there appear to be two distinct populations in the IC ensemble: one with a mode around $0 \mathrm{Kday}^{-1}$, and another with a mode around $-12 \mathrm{~K} \mathrm{day}^{-1}$. Very few of the IC ensemble members are producing net warming at upper levels late in the simulation, while quite a few of the MP runs produce net heating. Examination of the values of the MP parameters indicates the majority of the lowlevel cooling and mid- and upper-level warming are associated with values of $a_{s}$ and $a_{g}$ larger than the default.

Overall, changes in IC appear to have more effect on updrafts and latent heating than MP early in the simulations, with MP having the largest influence in the later stages of development. The influence of both IC and MP on the vertically integrated and vertically resolved quantities increases with time, with the largest variability seen in the later stages of development.

\section{Quantitative sensitivity analysis}

In this section, we seek to identify the specific factors that produce the largest response in each of the model output quantities of interest. The simplest way to quantitatively examine parameter-response relationships is via one-at-a-time (OAT) analysis, in which a single control parameter is varied, while the values of all other parameters are fixed to a default value. The fundamental quantity measured in an OAT analysis is the
TABLE 6. Standard deviation of the ensemble of mean latent heating rates $\left(\mathrm{K} \mathrm{day}^{-1}\right)$ generated from randomly drawn parameter and initial-condition values in each of the three time intervals.

\begin{tabular}{lccc}
\hline \hline & Developing & Mature & Dissipating \\
\hline $\begin{array}{l}\text { Microphysics } \\
\text { Upper }\end{array}$ & 0.23 & 4.40 & \\
$\quad$ Middle & 0.31 & 3.54 & 5.98 \\
$\quad$ Low & 0.33 & 2.17 & 2.83 \\
Initial conditions & & & \\
$\quad$ Upper & 2.42 & 5.99 & 7.30 \\
$\quad$ Middle & 5.03 & 5.69 & 6.81 \\
Low & 1.20 & 1.54 & 1.89 \\
\hline
\end{tabular}

elementary effect. Consider a vector of $N$ parameters $\mathbf{x}=$ $\left[x_{1}, x_{2}, \ldots, x_{N}\right]$ and a single output quantity of interest (response) $y=f(\mathbf{x})$, where we have made explicit the fact that $y$ is a function of the parameters $\mathbf{x}$. The elementary effect of a perturbation to parameter $x_{j}$ on $y$ can be computed as

$$
d_{i, j}=\left[f\left(x_{1}, \ldots, x_{j}+\Delta x_{j}, \ldots, x_{N}\right)-f\left(x_{1}, \ldots, x_{j}, \ldots, x_{N}\right)\right] / \Delta x_{j},
$$

where $\Delta x_{j}$ denotes a change in parameter $x_{j}$, and we have added an index $i$ to account for the fact that the elementary effect may be computed several times for different values of the remaining parameters $x_{k \neq j}$. For the sake of comparison among parameters $x_{j}$ and various outputs $y$, it is common practice to normalize each $x_{j}$ using its predefined minimum $\left(x_{\min }\right)$ and maximum $\left(x_{\max }\right)$ values:

$$
\hat{x}_{j}: x_{j} \rightarrow \frac{x_{j}-x_{\min }}{x_{\max }-x_{\min }} .
$$

The set of normalized $\hat{\mathbf{x}}$ represents a unit hypercube of dimension $N$. The simplest OAT experiment computes a Jacobian, and requires $N+1$ simulations, where $N$ is the total number of parameters. A more thorough experiment varies each parameter across a range (e.g., to assess the functional response of the outcome $y$ to a change in each parameter $x_{j}$ ). Assuming an equivalent number of perturbations $M$ applied to each of the $N$ parameters, this experiment requires $M N+1$ simulations. The issue is that each type of experiment yields sensitivity or response relative to fixed parameter values. If sensitivities change with changes in the default values of the other parameters, the OAT analysis will not detect this.

Morris screening, or Morris one-at-a-time techniques (MOAT; Morris 1991; Covey et al. 2013) are an extension to OAT perturbation techniques that compute the change in an outcome $y$ for a given change in input $x_{j}$ 
several times: for multiple values of $x_{j}$, and for various baseline (or reference) values of the other $x_{k \neq j}$ parameters. As in OAT, the computational cost of MOAT grows linearly with the number of control parameters. In MOAT, baseline parameter values are modified by following a so-called MOAT path. In brief, once parameter values have been normalized, a single MOAT path consists of $N+1$ simulations, and is constructed via the following procedure:

1) Divide the normalized parameter range $[0,1]$ into $L$ levels, where $L$ is usually an even number.

2) Draw a random $l$ point in the parameter range for each of the $N$ parameters, which produces a set of normalized parameter values. Convert the parameters back to their nonnormalized values by multiplying each parameter by its range of values and then adding the result to the minimum parameter value, and then run the model to produce a vector of outputs $\mathbf{y}$ that contains all of the model output quantities of interest.

3) Starting from the set of randomly generated normalized parameters in Eq. (2), perturb the first parameter $x_{1}$ by a factor $\Delta x$ given by

$$
\Delta x=\frac{L}{2(L-1)} .
$$

Convert this and the other parameters to their nonnormalized values, and run the model with this perturbed set of parameters.

4) Repeat step 3 for all other parameters $x_{2}, \ldots, x_{N}$.

The result is a Jacobian: a set of $N+1$ simulations of all parameters perturbed with respect to the randomly drawn $l$-point reference determined in step 2 . The same number of levels $L$ are used for each MOAT path, and after following $M$ paths, there will be $(N+1) M$ model runs. Differences between various pairs of simulations in a single MOAT path are used to compute a set of elementary effects. As such, there will be $M$ estimates of $d_{i, j}$, with $i$ the index of the MOAT path. Diagnostics of parameter sensitivity utilize the set of elementary effects; specifically, the mean and standard deviation of the absolute value of the elementary effect $\left|d_{i, j}\right|$ over all $M$ perturbations. The absolute value of $d_{i, j}$ is used in the computation of $\mu_{j}^{*}$ and $\sigma_{j}$ to avoid the possibility of underrepresenting the main effect in situations for which the elementary effect may be positive or negative. These are computed as

$$
\mu_{j}^{*}=\frac{1}{M} \sum_{i=1}^{M}\left|d_{i, j}\right|
$$

and

$$
\sigma_{j}=\sqrt{\frac{1}{M} \sum_{i=1}^{M}\left(\left|d_{i, j}\right|-\mu_{j}^{*}\right)^{2}},
$$

respectively. Ultimately, the calculation results in a mean and standard deviation of the absolute value of the elementary effects for each parameter $x_{j}$, and is repeated for all output variables of interest in the vector of outputs $\mathbf{y}$. Possible outcomes of the MOAT analysis for each parameter $x_{j}$-response $y$ pair include, but are not limited to the following:

1) Large mean, small sigma: the parameter has a large influence on $y$, and the effect of parameter variations is largely independent of the values of the other parameters.

2) Large mean, large sigma: the parameter has a large influence on $y$, but this influence depends on the values of other parameters (indicates nonlinearity or interaction among parameters).

3) Small mean, large sigma: the parameter generally has a small influence on $y$, except in certain limited circumstances, in which its influence is large.

4) Small mean, small sigma: the parameter $x_{j}$ is generally noninfluential.

To diagnose which of these four scenarios a given parameter-output pair falls into, it is common to plot $\sigma$ versus $\mu^{*}$. In our experiments, we divided the parameters into $l=20$ levels, and $\operatorname{ran} M=20$ MOAT paths. This resulted in $(N+1) M=220 \mathrm{GCE}$ simulations for the set of 10 microphysical parameters, and 420 simulations for the set of 20 initial condition EOF-PC pairs. In the analysis that follows, we first present results of the MOAT analysis for convective vertical motion and heating in the latter stages of the storm life cycle, then provide an overview of the results for all output variables and times.

\section{a. Influence of MP and IC on convective updrafts and heating}

In the Monte Carlo ensemble, changes in IC and MP produced a relatively large response in the convective updrafts and latent heating in the final stages of the storm development (Figs. 6 and 7). The MOAT analysis allows us to determine which MP and IC factors had the largest effect, and the degree to which they interact with other factors. Plots of the $\mu^{*}$ versus $\sigma$ for MP are shown in Figs. $8 \mathrm{a}-\mathrm{c}$ and $8 \mathrm{~d}-\mathrm{f}$ for updrafts and heating, respectively. The most influential parameters (those with a large value of $\left.\mu^{*}\right)$ are the autoconversion threshold $q_{c 0}$, snow $\left(a_{s}\right.$ and $\left.b_{s}\right)$ and graupel $\left(a_{s}\right.$ and $\left.b_{s}\right)$ fall speed parameters, and the slope intercept of the rain PSD $N_{0 r}$. The threshold $q_{c 0}$ has by far the largest effect on the 
upper-level updrafts and heating (Figs. 8c,f), with a mean main effect that is more than double that of any of the other parameters. In addition, the mean elementary effect is approximately 3 times larger than the standard deviation, indicating that $q_{c 0}$ is influential regardless of the values of the other microphysical parameters. The autoconversion threshold controls the partition of liquid between cloud droplets and rain, and decreases in its value produce larger amounts of rain at the expense of small cloud droplets. It is likely that the influence on updrafts and heating is due to higher $q_{c 0}$ values resulting in larger amounts of liquid droplets lofted to higher levels. Subsequent freezing (and the associated enthalpy of phase change) result in increased updraft speeds and larger heating rates.

At middle levels (Figs. 8b,e), $q_{c 0}$ continues to have the dominant effect on heating, while the fall speed parameters for snow and graupel begin to exert an influence on the updraft speeds. As with the upper levels, larger $q_{c 0}$ values, and the associated increase in freezing of cloud droplets is likely the primary reason for its influence. Changes in snow and graupel fall speeds influences the sorting of hydrometeors, and changes in settling of ice particles will influence the heating (e.g., by changing the mass of ice available for riming and vapor deposition) and consequently also the vertical motion.

At lower levels (Figs. 8a,d), the snow fall speed coefficient has a large effect on the upward motion, but as $\mu^{*}$ is approximately equal to $\sigma$, its effect depends on the values of other parameters. In addition to $a_{s}$, the rain PSD intercept and graupel fall speed exponent $b_{s}$ affect the low-level heating. The likely reason that the rain PSD intercept has the largest influence on the low-level heating is its control over the number of raindrops of different sizes. At high values of $N_{0 r}$ (large intercept), there will be larger numbers of small drops, relative to small values of $N_{0 r}$. For a given liquid water content, a change in drop size modifies the evaporation of rain, which in turn has an influence on the evaporative cooling. We hypothesize that many of the large values of negative LHR seen in Fig. 7i are associated with large values of $N_{0 r}$. As the default value of $N_{0 r}$ is quite small relative to the range of possible values, it is to be expected that larger values of $N_{0 r}$ (larger numbers of small drops, relative to large drops) will result in greater evaporation and larger negative values of LHR.

In contrast to MP, there are a larger number of IC parameters that contribute substantively to changes in updraft speed and latent heating. If we focus on those that have the largest influence, we see that the second, third, and fourth EOFs of temperature consistently have a large effect on convective dynamics and heating, though in many cases $\sigma$ is greater than or equal to $\mu^{*}$, indicating the influence depends on other variables. A close examination of the results indicates that the lowand midlevel vertical velocity and heating (Figs. 8g,h,j,k) are most influenced by the third EOF of the temperature, which primarily changes the thermal structure of the lower to middle free troposphere $(600-800 \mathrm{hPa})$. Modification of the temperature (and via the $\mathrm{RH}$ also the water vapor) in the lower to middle free troposphere has been shown to be related to the onset of strong precipitation in the tropics (Muller et al. 2009; Neelin et al. 2009; Schiro et al. 2016) due to its effect on the lower-free-tropospheric buoyancy. EOFs 2 and 4 of the temperature profile also influence lower-freetroposphere temperature (with EOF4 also having an effect on the upper troposphere) and are the most influential IC parameters on the upper-level vertical velocity (Fig. 8i). The mid- and upper-level latent heating (Figs. $8 \mathrm{k}, 1$ ) are also affected by changes to the $u$ - and $v$-direction winds, with the zonal wind having a larger effect on the midlevels. Changes in shear are known to have an effect on the relative location of the low-level inflow and updrafts and locations of precipitation in the middle and upper troposphere, and it is likely the case that this is the mechanism in our simulations as well. Our simulation domain is too small to permit true upscale growth of convection on the mesoscale.

\section{b. Summary measures of parameter influence from the MOAT ensemble}

If we sum the mean main effect $\mu^{*}$ for each variable at each time (and over all layers, in the case of $W+$ and LHR), combining the mean main effect for each quantity of interest (QOI) into a single summed main effect over the entire simulation, we can rank the influence of each parameter on each output variable. We have summarized the parameter-QOI rankings in Figs. 9a and $9 \mathrm{~b}$ for the microphysics parameters and initial conditions, respectively. These figures show which parameters and EOFs have the dominant influence on the outcome. In particular, the warm rain parameters $q_{c 0}$ and $N_{0 r}$ clearly have the greatest influence on most variables, followed by the snow and graupel fall speed parameters. The snow and graupel density have a smaller effect, while the snow and graupel PSD slope intercept parameters consistently rank last. We note that it is possible that the graupel slope intercept may exert greater influence in midlatitude squall lines (e.g., Gilmore et al. 2004). Temperature EOFs, especially T2, T3, and T4, clearly exert the largest effect on all output variables, followed by the third EOF of the $u$-direction wind, and EOFs 1-3 of the RH.

We may obtain more information on the specific parameter influence on each output variable at each time 
Microphysics

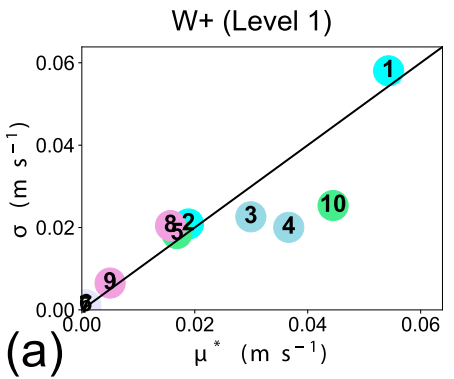

LHR (Level 1)

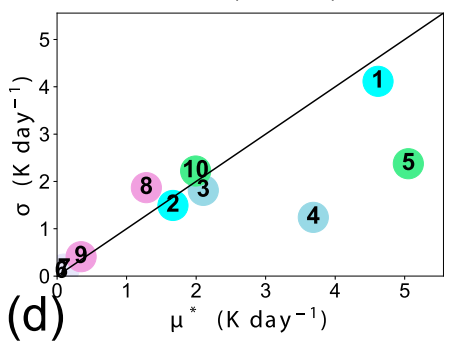

(e)

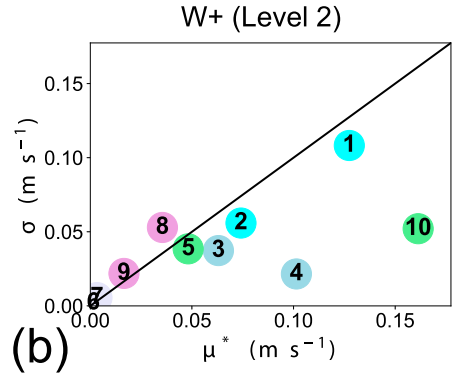

LHR (Level 2)

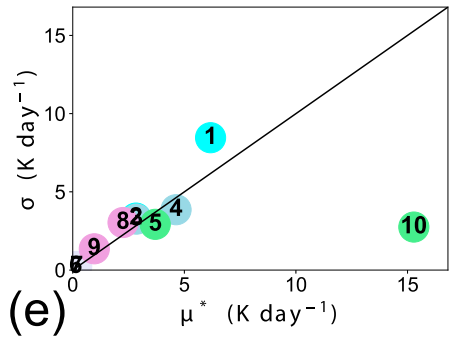

Initial Conditions

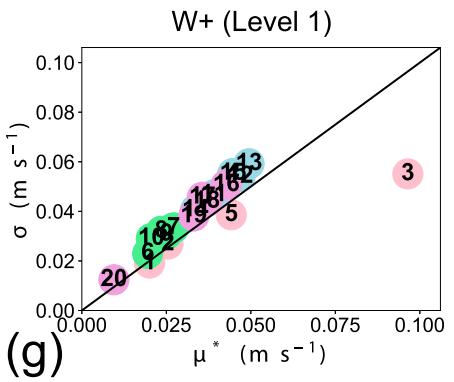

LHR (Level 1)

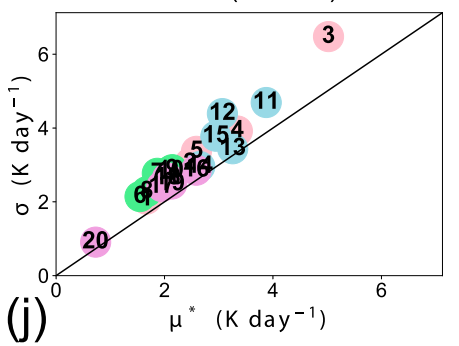

W+ (Level 2)

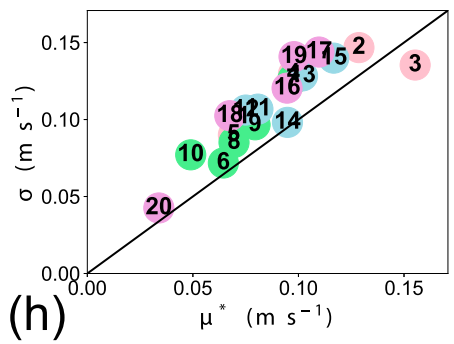

LHR (Level 2)

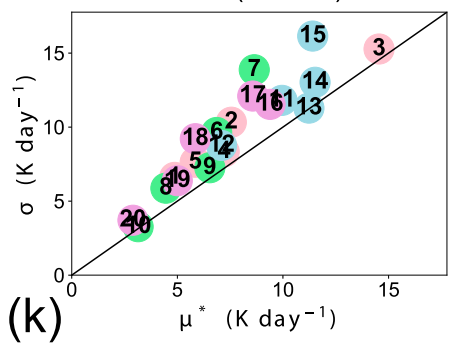

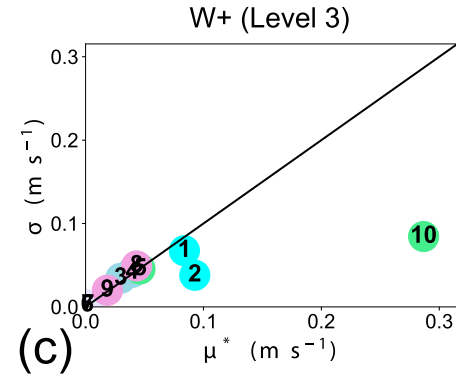

(1) $a_{s}$

(2) $b_{s}$

(3) $a_{g}$ (4) $b_{\mathrm{g}}$ $5 \mathrm{~N}_{\mathrm{or}}$ $6 \mathrm{~N}_{0 \mathrm{~s}}$ $7 \mathrm{~N}_{0 \mathrm{~g}}$ $8 \rho_{\mathrm{s}}$ $9 \rho_{\mathrm{s}}$ $10 q_{c 0}$

(f)

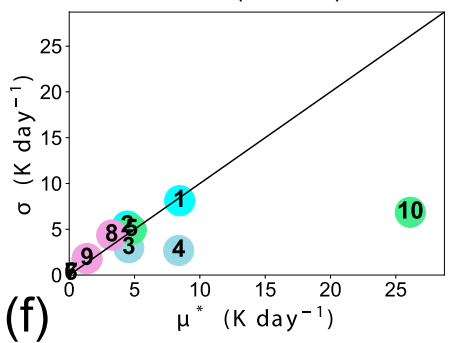

$1 \mathrm{~T}_{1} \quad 11 \mathrm{U}_{1}$

$\begin{array}{llll}2 & \mathrm{~T}_{2} & 12 & \mathrm{U}_{2}\end{array}$

(3) $\mathrm{T}_{3} \quad 13 \mathrm{U}_{3}$

$4 \mathrm{~T}_{4} \quad 14 \mathrm{U}_{4}$

(5) $\mathrm{T}_{5} \quad 15 \mathrm{U}_{5}$

(6) $\mathrm{RH}_{1} \quad 16 \mathrm{~V}_{1}$

(7) $\mathrm{RH}_{2} \quad 17 \mathrm{~V}_{2}$

$8 \mathrm{RH}_{3} 18 \mathrm{~V}_{3}$

(9) $\mathrm{RH}_{4} 19 \mathrm{~V}_{4}$

$10 \mathrm{RH}_{5} 20 \mathrm{~V}_{5}$

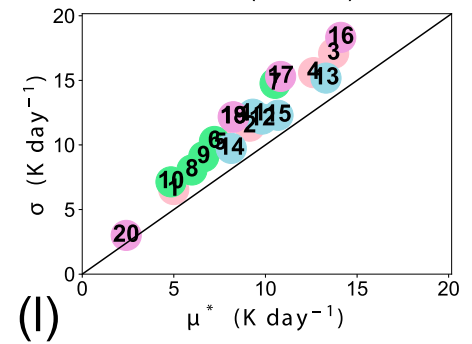

(I)

FIG. 8. Morris one-at-a-time results for the response of (a)-(c),(g)-(i) upward vertical velocity and (d)-(f),(j)-(l) latent heat
release during the dissipating phase of convection to changes in (a)-(f) microphysics parameters and (g)-(l) initial conditions. Microphysical parameters are labeled and colored according to the parameter set: cyan for the snow fall speed parameters, light blue for the graupel fall speed parameters, light purple for the snow and graupel PSD intercept parameters, purple for the snow and graupel densities, and green for the autoconversion and rain slope intercept parameters. Each initial-condition EOF is labeled with a number and colored by variable. Red corresponds to temperature, green to RH, blue to zonal wind, and purple to meridional wind. The black line in each panel denotes where the mean and sigma are equivalent. Columns show (left) low, (center) middle, and (right) upper levels. 

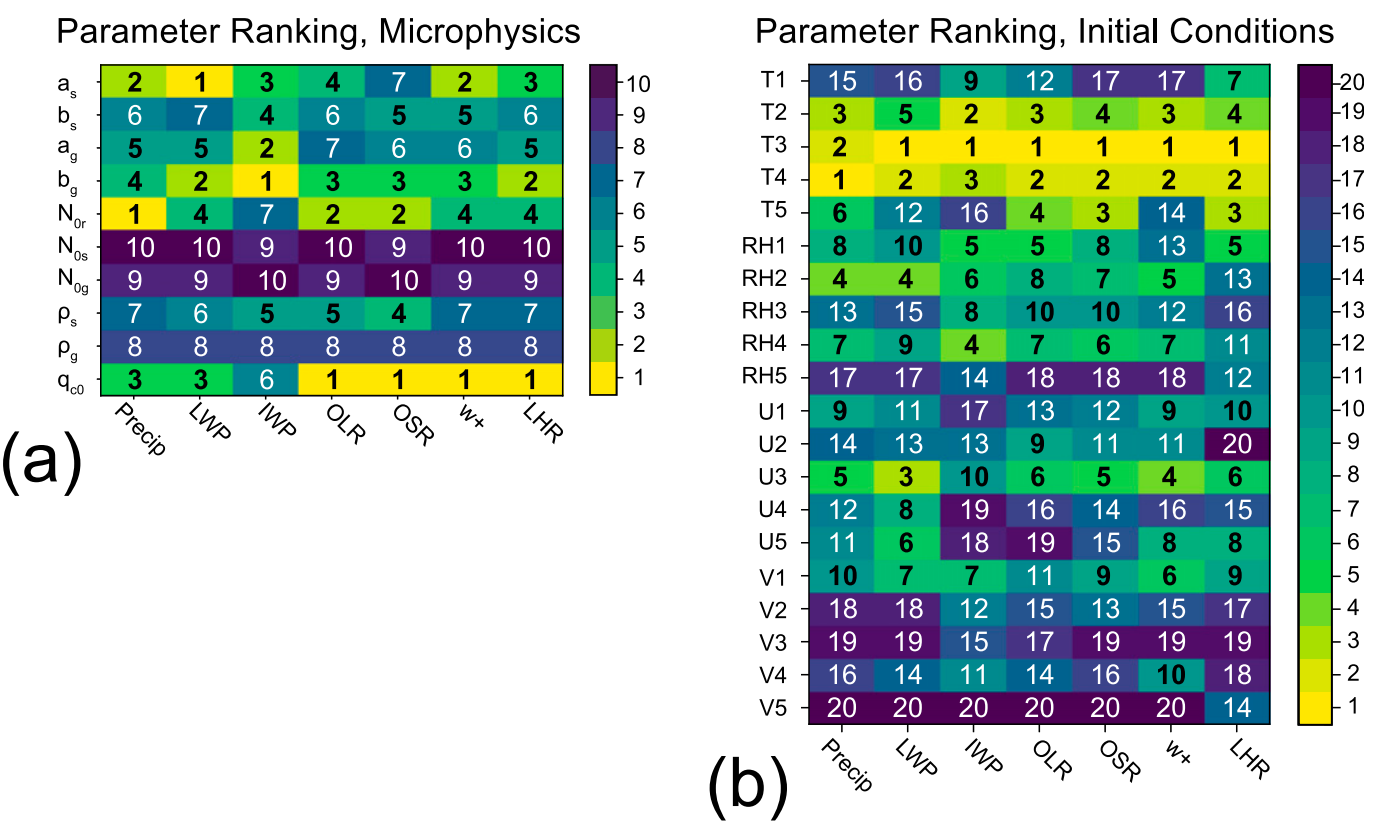

FIG. 9. Rank of each (a) microphysical parameter and (b) initial-sounding EOF for each output quantity of interest, averaged over all times and (for $W+$ and LHR) all vertical levels. Ranks are depicted in both color shading and text, with boldface black text reserved for the top-5 microphysical parameters and the top-10 initial conditions.

by dividing the mean main effect $\mu^{*}$ by the standard deviation of the main effect $\sigma$ (Fig. 10). If the effect ratio is less than $1(<100 \%)$ for a given parameter, then the mean of the main effect is smaller than its standard deviation. As mentioned previously, this means that there is either nonlinearity in the parameter-output relationship, or significant interactions with other parameters. If the ratio is greater than $100 \%$, but less than $300 \%$, this generally means low to moderate nonlinearity/ interaction. Ratios greater than $300 \%$ indicate a strong linear response; the model output variable of interest is sensitive to changes in the parameter regardless of the value of the parameter itself, or the values of the other control variables (Morris 1991). Of the set of microphysics parameters (Fig. 10a), $q_{c 0}$ and $N_{0 r}$ consistently produce ratios $>100 \%$, with many exceeding $300 \%$, though there is more nonlinearity (ratios $<100 \%$ ) for $N_{0 r}$ during the dissipating phase. The ice particle fall speeds (especially those for graupel) have a relatively high ratio during all phases of development, and the graupel fall speed exponent has an approximately linear effect on select output variables at all times, being the only fall speed parameter that exhibits a ratio greater than $300 \%$. The fact that the warm rain and ice hydrometeor fall speed parameters have a consistent influence on many of the output variables, independent of the values of other parameters, does not necessarily mean that their influence is linear. It simply indicates that they always have an effect. The specific interactions and connections between variables (e.g., the fact that larger numbers of small cloud and raindrops, via increases in $q_{c 0}$ and $N_{0 r}$, may lead to more riming), requires a more detailed analysis that is beyond the scope of the current study.

The mean to standard deviation ratios of the sounding EOFs are plotted in Fig. 10b, and it is immediately apparent that there are stronger interactions among the IC parameters than MP, as the ratios are systematically lower for most EOFs. Of the IC, EOFs of temperature (particularly the third and fourth EORs) have relatively larger ratios (consistently greater than $100 \%$, and occasionally larger than $200 \%$ ) through the length of the simulation, though the ratios generally decrease with time. Ratios for the winds are commonly smaller than the ratios for $T$ and $\mathrm{RH}$, indicating their effect on simulation output is influenced by changes in other sounding variables. The RH ratios are consistently around $100 \%$ for all times and EOFs (except the $\mathrm{RH} 1$ ratio for OLR in the developing phase, which is large). Note, however, that the magnitude of the sensitivity is still rather small (mean of $\sim 3 \mathrm{~W} \mathrm{~m}^{-2}$ ). Remember that a relatively low ratio of $\mu^{*}$ to $\sigma$ for a parameter simply indicates there is an interaction with one or more other parameters. It does not indicate the parameter has a smaller influence on the simulation outcome.

As a final metric, we plot the mean main effect $\mu^{*}$ divided by the range of output values (considered over 


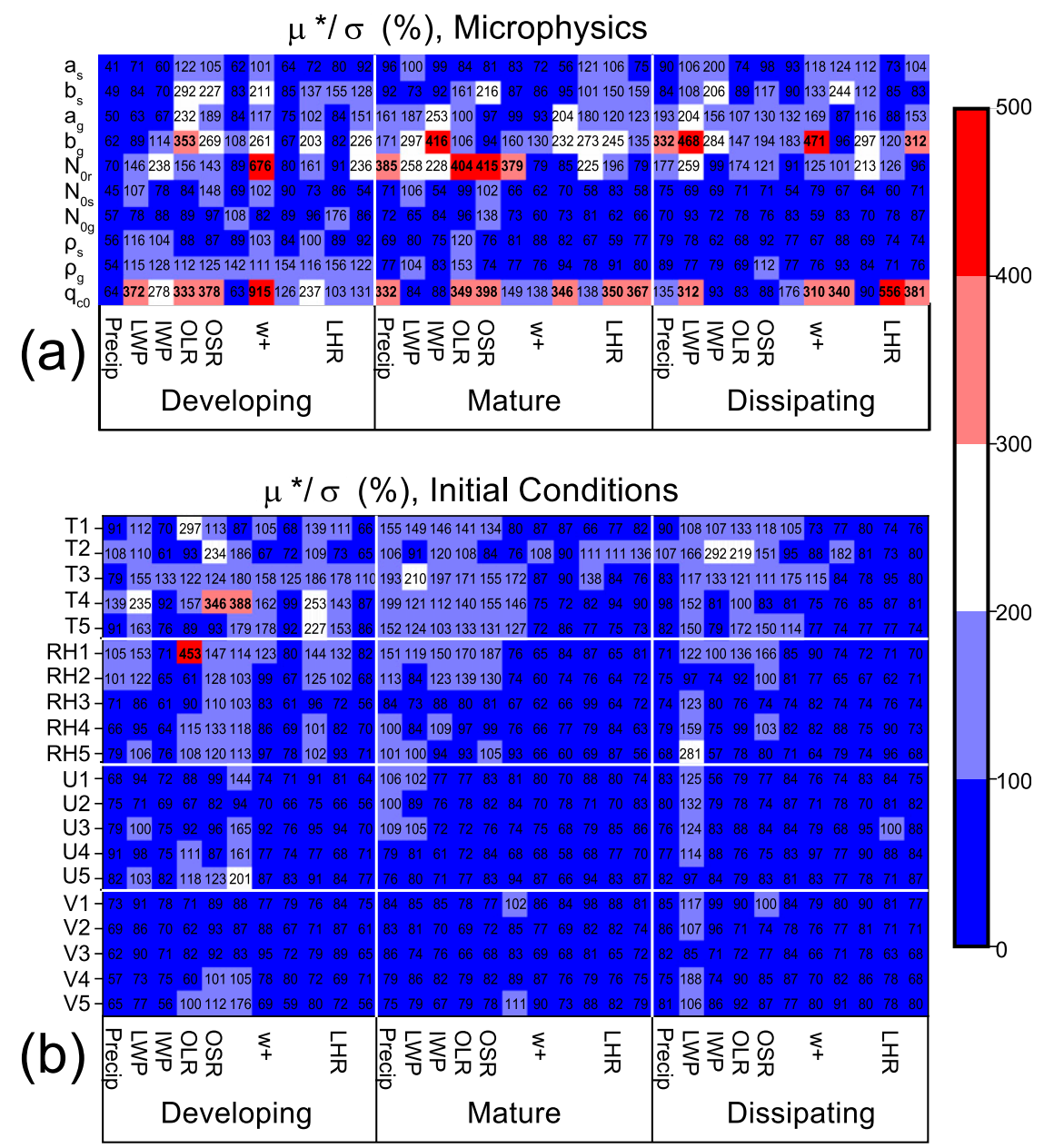

FIG. 10. Ratio (\%) of the mean main effect to the standard deviation for each (a) microphysical parameter and (b) initial-sounding EOF for the full set of output quantities of interest at each discrete time and (for $W+$ and LHR) level. Color shading indicates the approximate value. The actual ratio values are overlaid, with boldface indicating values exceeding $300 \%$.

all MOAT paths) for each control and output variable (Fig. 11). The result is indicative of the fraction of the variability in the output that is due to a change in a given control parameter. While this is not, strictly speaking, a computation of fraction of variance explained, it has a similar connotation, and is perhaps the most straightforward way to measure parameter influence from the MOAT analysis. Of the microphysics parameters, changes in $q_{c 0}$ frequently account for $25 \%$ or more of the variability in the model output. Interestingly, when measured in this fashion, the ice particle fall speeds are shown to have similar magnitude effect on the model output as the warm rain parameters during mature and dissipating phases of development. It is expected changes to parameters that control the warm rain processes will have an influence early. The fact that changes in warm rain continue to strongly affect the model output later in the storm development across all variables considered reflects the importance of the partition between rain and cloud on ice-phase processes. For example, an increase (decrease) in the number of small cloud droplets should result in an increase (decrease) in the amount of liquid available for freezing higher in the storm. This in turn affects the generation of ice hydrometeors, as well as the latent heating and vertical motion. Ice hydrometeor fall speed assumptions, in turn, affect the amount of ice that precipitates, further affecting the ice and liquid water content and radiative fluxes. Ice precipitation also affects the latent heating through its influence on how much ice is available for freezing. While all of these processes have been well understood for some time, our analysis helps to quantify the sensitivity of specific output variables to changes in particular parameters at each stage of development. 


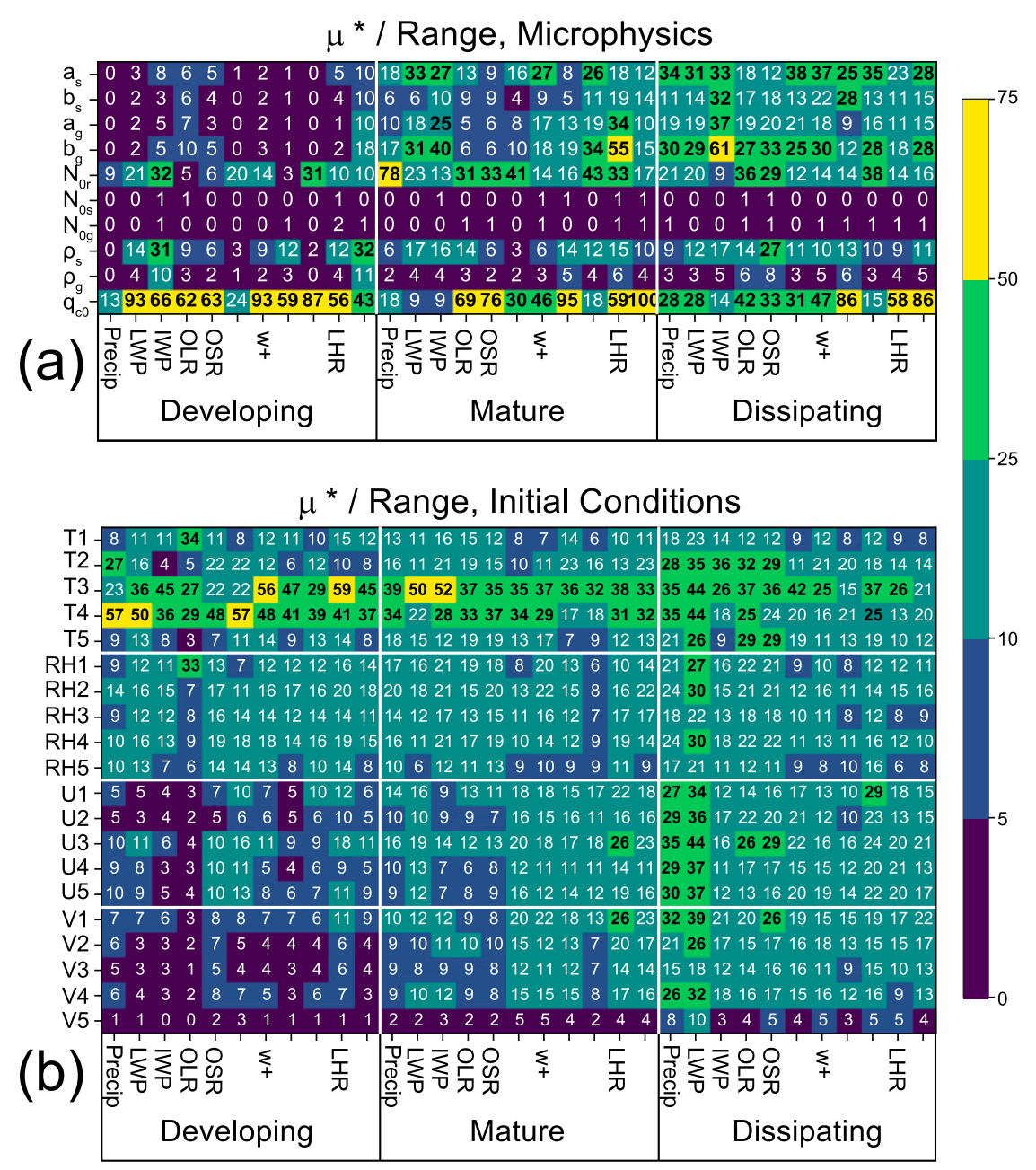

FIG. 11. Ratio (\%) of the mean main effect $\mu^{*}$ to the range of each output variable (maximum value - minimum value) over all simulations included in the full set of MOAT paths for each (a) microphysical parameter and (b) initial-sounding EOF for the full set of output quantities of interest at each discrete time and (for $W+$ and LHR) level. Color shading depicts the approximate ratio. The actual ratio values are overlaid, with boldface black text indicating ratios greater than $0.25(25 \%)$

As was shown in the plots of parameter rank (Fig. 9), modifications to the third and fourth EOF of temperature (T3 and $\mathrm{T} 4)$ consistently produce the largest magnitude changes in all outcomes at all times, contributing commonly upward of $30 \%$ of the variability in the output. Perturbations to the sounding using these EOFs produce changes in the static stability of the lower free troposphere (in the case of both $\mathrm{T} 3$ and T4) and also the upper troposphere (in the case of T4). EOFs of RH and wind begin to have more effect in the mature and dissipating phases, especially on the liquid water path. The sensitivity in LWP makes sense, as changes in RH in the sounding will change the amount of water vapor available for condensation, and the fact that modifications are applied as a percent means that there are larger changes in water vapor mass lower in the troposphere where temperatures are above freezing. The increasing influence of wind with increasing simulation time reflects the organizing influence of shear on convective structure, which manifests primarily in mature and dissipating phases of convective development.

\section{Implications for ensemble generation and design of observing systems}

Overall, the MOAT analysis reveals which parameters exert the largest influence at each time, and which variable(s) they have the largest effect on. They also indicate which parameters have a consistent influence on model output (independent of the values of other 
parameters), and which have interactions with other parameters. As has been indicated in previous studies, a relatively small fraction of the parameters controls the outcome. By quantitatively identifying the most significant control parameters, we determine the subset that are worthy of more in-depth study, as well as those that may be most productively used to produce variability in ensembles of convective events. In particular, we find that perturbations to warm rain and ice fall speed parameters would provide the largest range of responses in an ensemble prediction system. In addition, influence of these parameters is felt through the duration of the simulations, with the influence (and consequently ensemble spread) increasing with time. In contrast, changes to the convective thermodynamic environment are felt almost immediately, with changes to the wind profile manifesting later on. Consistent with previous studies, we find that changes to lower- to middle-freetroposphere temperature and humidity, as well as zonal wind shear, have the largest influence on the simulation outcomes. Overall, we have found that, of the 30 total control factors evaluated, a subset of approximately $10-15$ is most important. This is information that could be used to inform ensemble forecasting and data assimilation. We wish to point out that all of the aforementioned results are only truly applicable to simulations run with the GCE single-moment cloud microphysics scheme. Even so, a recent study involving the Morrison and Milbrandt (2015) two-moment scheme indicates many of the parameters we have identified as important (e.g., ice particle fall speeds and parameters related to warm rain processes) are also influential in a two-moment bulk scheme (Morales et al. 2018).

We may also use the results of this sensitivity study to say something about the observational requirements for deep convection. A natural complement to the ensemble forecast problem is the consideration of which variables are most critically in need of constraint in the model. In this case, we find that observations of temperature and humidity in the lower and middle free troposphere are crucial, as are observations of the wind profile through the depth of the troposphere. From the cloud microphysical parameter sensitivity experiments, we find that the factors that influence the rain particle size distribution and rain initiation exert by far the greatest control over convective outcomes, closely followed by the ice hydrometeor fall speeds. All of these are related to hydrometeor diameters, and we hypothesize that the use of multifrequency radar (perhaps also with Doppler capability) may be quite helpful in this regard, provided the measurements have sufficient sensitivity to discriminate between precipitating and nonprecipitating cloud. For land-based radars, and potential spaceborne radars with relatively large incidence angles, polarimetric capability would likely be useful as well.

\section{Summary and conclusions}

In this study, we have used ensembles of simulations of a tropical deep convective storm to explore the relative sensitivity of deep convection to changes in cloud microphysics and the convective environment. We perturbed cloud microphysical parameters (MP) across their physically realistic ranges, and modified the thermodynamic state and wind profile (IC) using perturbations that were consistent with patterns of variability in the tropics, and with magnitudes consistent with uncertainties in radiosonde observations. We examined the effect of these perturbations on the model output hydrologic cycle, radiative fluxes, vertical velocity, and latent heating rates. We conducted two sets of experiments: one in which the control parameters were varied randomly (Monte Carlo), and another in which they were varied systematically using a Morris one-at-a-time sensitivity analysis technique. The key findings of our study include the following:

1) Changes in both cloud microphysics and initial conditions lead to changes in the model hydrologic cycle, radiative fluxes, vertical velocity, and latent heating that are of the same order of magnitude. These changes are initially small but amplify with time.

2) Perturbations to cloud microphysics produce a range of precipitation rates, but rain amounts during the mature phase of convection in all simulations remain greater than zero. In contrast, small perturbations to the initial sounding can cause, in some cases, a complete cessation of rainfall in the model.

3) Perturbations to microphysics cause larger changes in mature- and late-stage LWP as well as late-stage IWP, while changes in the sounding have larger effects on mature stage IWP and OLR and OSR at all output times. They produce changes in precipitation rate that are similar in magnitude. Distributions of column integral model output variables are commonly skewed, and at times have a mean or mode that differs from the control value(s), indicating nonlinearity in the model control-response relationship for both IC and MP.

4) Changes in microphysics lead preferentially to decreases in latent heating at maturity, and increases in late-stage vertical velocity and latent heating, relative to the control simulation. Microphysical changes have a larger effect on low-level latent heating, producing cooling more readily than 
perturbations to the sounding. However, these outcomes are generally associated with large ice fall speed parameter values.

5) Of the 30 total control factors we tested, a subset of $10-15$ produced the largest variability in the convective hydrologic cycle, radiative fluxes, vertical mass flux, and latent heating. These included the warm rain parameters (autoconversion threshold and slope intercept of the rain particle size distribution), the graupel and snow fall speed parameters, and a few key vertical structures in temperature, humidity, and zonal wind. The implication is that a smaller subset of the total number of control variables may be used to produce variance in an ensemble forecasting context. It also implies the need for observational constraint on the thermodynamic state of the lower to middle free troposphere, and also to the need for observations of the particle size distributions of both liquid and ice hydrometeors.

6) The fact that warm rain parameters exert a strong influence through the length of the simulation reflects their importance to both the warm rain processes and the ice processes and consequent heating and vertical motion in the middle and upper troposphere. The fact that EOFs of temperature that peak in the lower to middle free troposphere exert the strongest influence on the solution of any of the sounding parameters reflects the importance of changes in lower- to middle-free-troposphere stability and humidity on the development of deep convection.

The results highlight the importance of accurate initial conditions, and also proper representation (and, if possible, constraint) of uncertainty in the model physics. It was particularly interesting to us to find that changes to cloud microphysical parameters produced the same order of magnitude change in model output as did changes to initial conditions. The implication is that improved representation of convection in weather and climate projections will require accurate representation of both the convective environment (context) as well as the details of cloud microphysical processes.

In closing, we note that there are several caveats to this study. First, we have used a specific case of deep convection that had relatively weak buoyancy and weak to moderate shear. While simulations (and observations) of this case showed a loosely organized and approximately linear system, we expect that convection developing in a low-CAPE and low-shear environment may be more sensitive to perturbations in microphysics and environment than systems developing in high-CAPE and high-shear environments. We are currently working to expand this study to include convective systems that develop in fundamentally different environments.

There are also limitations associated with the model configuration. Specifically, we have used a rather coarse $(2 \mathrm{~km})$ horizontal grid spacing, and the model was run with a relatively simple single-moment bulk microphysical parameterization. While our control simulation exhibited overall development that is similar to a high-resolution counterpart (and to observations of the case), it was clearly not able to reproduce the full spectrum of shallow to midlevel clouds. We are currently conducting perturbation experiments using a higher-resolution model configuration and have found in our initial results that, while the details differ, the sensitivity of bulk measures of convection in the high-resolution model (e.g., vertical motion, latent heating, and precipitation) is qualitatively similar to sensitivity in the coarse-resolution model.

In addition, while we are confident in the robustness of our microphysics parameter sensitivity experiments, we are well aware that they are specific to the microphysical scheme we used. Perturbation of parameters in a different single-moment scheme, or in a two- or higher-moment scheme, may produce qualitatively different results. Similarly, the EOFs-PCs we use to perturb the model sounding were derived from only a few sites in the tropics. While they constitute a database large enough to encompass a wide variety of environments, they will almost certainly not span the full range of thermodynamic and dynamic contexts in which convection develops. We should also note that this sounding database did not only include convective profiles. It also included suppressed conditions, along with preconvective and postconvective environments. We have chosen to use EOFs and PCs derived from the full database, but acknowledge that our results may have been different had we restricted our profiles only to those that were taken in proximity to deep convection.

Acknowledgments. This work was supported by NASA Interdisciplinary Research in Earth Science program Grant NNX14AG68G, as well as by the U.S. Office of Naval Research Propagation of Intra-Seasonal Tropical Oscillations (PISTON) project. A portion of this research was carried out at the Jet Propulsion Laboratory, California Institute of Technology, under a contract with the National Aeronautics and Space Administration.

\section{REFERENCES}

Benjamin, S. G., and Coauthors, 2016: A North American hourly assimilation and model forecast cycle: The Rapid Refresh. Mon. Wea. Rev., 144, 1669-1694, https://doi.org/10.1175/ MWR-D-15-0242.1. 
Bergemann, M., and C. Jakob, 2016: How important is tropospheric humidity for coastal rainfall in the tropics? Geophys. Res. Lett., 43, 5860-5868, https://doi.org/10.1002/2016GL069255.

Böing, S. J., A. P. Siebesma, J. D. Korpershoek, and H. J. J. Jonker, 2012a: Detrainment in deep convection. Geophys. Res. Lett., 39, L20816, https://doi.org/10.1029/2012GL053735.

— - H. J. J. Jonker, A. P. Siebesma, and W. W. Grabowski, 2012b: Influence of the subcloud layer on the development of a deep convective ensemble. J. Atmos. Sci., 69, 2682-2698, https://doi.org/10.1175/JAS-D-11-0317.1.

Bryan, G. H., J. C. Wynguard, and J. M. Fritsch, 2003: Resolution requirements for the simulation of deep moist convection. Mon. Wea. Rev., 131, 2394-2416, https://doi.org/10.1175/ 1520-0493(2003)131<2394:RRFTSO > 2.0.CO;2.

Bukowski, J., D. J. Posselt, J. S. Reid, and S. A. Atwood, 2017: Modes of thermodynamic and wind variability over the Maritime Continent. Atmos. Chem. Phys., 17, 4611-4626, https:// doi.org/10.5194/acp-17-4611-2017.

Chen, B., C. Liu, and B. E. Mapes, 2017: Relationships between large precipitating systems and atmospheric factors at a grid scale. J. Atmos. Sci., 74, 531-552, https://doi.org/10.1175/ JAS-D-16-0049.1.

Chou, M. D., and M. J. Suarez, 1999: A shortwave radiation parameterization for atmospheric studies. NASA Tech. Rep. NASA/TM-1999-10460, Vol. 15, 38 pp.

,,-- X.-Z. Liang, and M.-H. Yan, 2001. A thermal infrared radiation parameterization for atmospheric studies. NASA Tech. Rep. NASA/TM-2001-104606, Vol. 19, 55 pp.

Cifelli, R., W. A. Petersen, L. D. Carey, S. A. Rutledge, and M. A. F. da Silva Dias, 2002: Radar observations of the kinematic, microphysical, and precipitation characteristics of two MCSs in TRMM LBA. J. Geophys. Res., 107, 8077, https:// doi.org/10.1029/2000JD000264.

Covey, C., D. D. Lucas, J. Tannahill, X. Garaizar, and R. Klein, 2013: Efficient screening of climate model sensitivity to a large number of perturbed input parameters. J. Adv. Model. Earth Syst., 5, 598-610, https://doi.org/10.1002/jame.20040.

Crook, N. A., 1996: Sensitivity of moist convection forced by boundary layer processes to low-level thermodynamic fields. Mon. Wea. Rev., 124, 1767-1785, https://doi.org/10.1175/ 1520-0493(1996)124<1767:SOMCFB $>2.0 . C O ; 2$

Cui, Z., K. S. Carslaw, and A. M. Blyth, 2011: The coupled effect of mid-tropospheric moisture and aerosol abundance on deep convective cloud dynamics and microphysics. Atmosphere, 2, 222-241, https://doi.org/10.3390/ atmos 2030222 .

Derbyshire, S. H., I. Beau, P. Bechtold, J. Grandpeix, J. Piriou, J. Redelsperger, and P. M. Soares, 2004: Sensitivity of moist convection to environmental humidity. Quart. J. Roy. Meteor. Soc., 130, 3055-3079, https://doi.org/10.1256/qj.03.130.

de Rooy, W. C., and Coauthors, 2013: Entrainment and detrainment in cumulus convection: An overview. Quart. J. Roy. Meteor. Soc., 139, 1-19, https://doi.org/10.1002/qj.1959.

Eitzen, Z. A., and K. Xu, 2008: Sensitivity of a large ensemble of tropical convective systems to changes in the thermodynamic and dynamic forcings. J. Atmos. Sci., 65, 1773-1794, https:// doi.org/10.1175/2007JAS2446.1.

Ferrier, B. S., 1994: A double-moment multiple-phase four-class bulk ice scheme. Part I: Description. J. Atmos. Sci., 51, 249-280, https://doi.org/10.1175/1520-0469(1994)051<0249: ADMMPF $>2.0 . \mathrm{CO} ; 2$.

_ precipitation efficiencies in midlatitude and tropical squall simulations. Mon. Wea. Rev., 124, 2100-2125, https://doi.org/ 10.1175/1520-0493(1996)124<2100:FRFPEI >2.0.CO;2.

Fovell, R. G., and Y. Ogura, 1989: Effect of vertical wind shear on numerically simulated multicell storm structure. J. Atmos. Sci., 46, 3144-3176, https://doi.org/10.1175/1520-0469(1989) 046<3144:EOVWSO > 2.0.CO;2.

— , and P.-H. Tan, 1998: The temporal behavior of numerically simulated multicell-type storms. Part II: The convective cell life cycle and cell regeneration. Mon. Wea. Rev., 126, 551-577, https://doi.org/10.1175/1520-0493(1998)126<0551: TTBONS $>2.0 . \mathrm{CO} ; 2$.

Gilmore, M. S., J. M. Straka, and E. N. Rasmussen, 2004: Precipitation uncertainty due to variations in precipitation particle parameters within a simple microphysics scheme. Mon. Wea. Rev., 132, 2610-2627, https://doi.org/10.1175/MWR2810.1.

Grabowski, W. W., 2003: Impact of cloud microphysics on convective-radiative quasi equilibrium revealed by cloudresolving convective parameterization. J. Climate, 16, 3463-3475, https://doi.org/10.1175/1520-0442(2003)016<3463: IOCMOC $>2.0 . \mathrm{CO} ; 2$.

, and H. Morrison, 2016: Untangling microphysical impacts on deep convection applying a novel modeling methodology. Part II: Double-moment microphysics. J. Atmos. Sci., 73, 3749-3770, https://doi.org/10.1175/JAS-D-15-0367.1.

- X. Wu, and M. W. Moncrieff, 1999: Cloud-resolving modeling of tropical cloud systems during phase III of GATE. Part III: Effects of cloud microphysics. J. Atmos. Sci., 56, 2384-2402, https:// doi.org/10.1175/1520-0469(1999)056<2384:CRMOTC $>2.0 . C O ; 2$.

Hagos, S., and L. R. Leung, 2012: Large-scale environmental variables and transition to deep convection in cloud resolving model simulations: A vector representation. J. Adv. Model. Earth Syst., 4, M11001, https://doi.org/10.1029/2012MS000155.

Hannah, W. M., 2017: Entrainment versus dilution in tropical deep convection. J. Atmos. Sci., 74, 3725-3747, https://doi.org/ 10.1175/JAS-D-16-0169.1.

_ - B. E. Mapes, and G. S. Elsaesser, 2016: A Lagrangian view of moisture dynamics during DYNAMO. J. Atmos. Sci., 73, 1967-1985, https://doi.org/10.1175/JAS-D-15-0243.1.

Hernandez-Deckers, D., and S. C. Sherwood, 2016: A numerical investigation of cumulus thermals. J. Atmos. Sci., 73, 41174136, https://doi.org/10.1175/JAS-D-15-0385.1.

Heymsfield, A. J., A. Bansemer, P. R. Field, S. L. Durden, J. L. Smith, J. E. Dye, W. Hall, and C. A. Grainger, 2002: Observations and parameterizations of particle size distributions in deep tropical cirrus and stratiform precipitating clouds: Results from in situ observations in TRMM field campaigns. J. Atmos. Sci., 59, 3457-3491, https://doi.org/10.1175/15200469(2002)059<3457:OAPOPS $>2.0 . \mathrm{CO} ; 2$.

Hohenegger, C., and B. Stevens, 2013: Preconditioning deep convection with cumulus congestus. J. Atmos. Sci., 70, 448-464, https://doi.org/10.1175/JAS-D-12-089.1.

Holloway, C. E., and J. D. Neelin, 2009: Moisture vertical structure, column water vapor, and tropical deep convection. J. Atmos. Sci., 66, 1665-1683, https://doi.org/10.1175/2008JAS2806.1. , and - 2010: Temporal relations of column water vapor and tropical precipitation. Atmos. Sci., 67, 1091-1105, https:// doi.org/10.1175/2009JAS3284.1.

Houze, R. A., Jr., 2004: Mesoscale convective systems. Rev. Geophys., 42, RG4003, https://doi.org/10.1029/2004RG000150.

Johnson, R. H., and X. Lin, 1997: Episodic trade wind regimes over the western Pacific warm pool. J. Atmos. Sci., 54, 20202034, https://doi.org/10.1175/1520-0469(1997)054<2020: ETWROT $>2.0 . \mathrm{CO} ; 2$. 
Kim, D., and Coauthors, 2014: Process-oriented MJO simulation diagnostic: Moisture sensitivity of simulated convection. J. Climate, 27, 5379-5395, https://doi.org/10.1175/JCLI-D-1300497.1.

Kirshbaum, D. J., 2011: Cloud-resolving simulations of deep convection over a heated mountain. J. Atmos. Sci., 68, 361-378, https://doi.org/10.1175/2010JAS3642.1.

Kuang, Z., 2010: Linear response functions of a cumulus ensemble to temperature and moisture perturbations and implications for the dynamics of convectively coupled waves. J. Atmos. Sci., 67, 941-962, https://doi.org/10.1175/ 2009JAS3260.1.

Kumar, V. V., A. Protat, C. Jakob, and P. T. May, 2014: On the atmospheric regulation of the growth of moderate to deep cumulonimbus in a tropical environment. J. Atmos. Sci., 71, 1105-1120, https://doi.org/10.1175/JAS-D-13-0231.1.

Lang, S., W.-K. Tao, R. Cifelli, W. Olson, J. Halverson, S. Rutledge, and J. Simpson, 2007: Improving simulations of convective systems from TRMM LBA: Easterly and westerly regimes. J. Atmos. Sci., 64, 1141-1164, https://doi.org/10.1175/ JAS3879.1.

,$- \ldots$, X. Zeng, and Y. Li, 2011: Reducing the biases in simulated radar reflectivities from a bulk microphysics scheme: Tropical convective systems. J. Atmos. Sci., 68, 2306-2320, https://doi.org/10.1175/JAS-D-10-05000.1.

Lin, Y.-L., R. D. Farley, and H. D. Orville, 1983: Bulk parameterization of the snow field in a cloud model. J. Climate Appl. Meteor., 22, 1065-1092, https://doi.org/10.1175/15200450(1983)022<1065:BPOTSF $>2.0$. CO;2.

Locatelli, J. D., and P. V. Hobbs, 1974: Fall speeds and masses of solid precipitation particles. J. Geophys. Res., 79, 2185-2197, https://doi.org/10.1029/JC079i015p02185.

Mapes, B. E., 2004: Sensitivities of cumulus-ensemble rainfall in a cloud-resolving model with parameterized large-scale dynamics. J. Atmos. Sci., 61, 2308-2317, https://doi.org/10.1175/ 1520-0469(2004)061<2308:SOCRIA > 2.0.CO;2.

Masunaga, H., 2012: Short-term versus climatological relationship between precipitation and tropospheric humidity. J. Climate, 25, 7983-7990, https://doi.org/10.1175/JCLI-D12-00037.1.

_- 2013: A satellite study of tropical moist convection and environmental variability: A moisture and thermal budget analysis. J. Atmos. Sci., 70, 2443-2466, https://doi.org/10.1175/ JAS-D-12-0273.1.

Meyers, M. P., R. L. Walko, J. Y. Harrington, and W. R. Cotton, 1997: New RAMS cloud microphysics parameterization. Part II: The two-moment scheme. Atmos. Res., 45, 3-39, https:// doi.org/10.1016/S0169-8095(97)00018-5.

Mitchell, D. L., 1996: Use of mass- and area-dimensional power laws for determining precipitation particle terminal velocities. J. Atmos. Sci., 53, 1710-1723, https://doi.org/10.1175/ 1520-0469(1996)053<1710:UOMAAD>2.0.CO;2.

Morales, A., H. Morrison, and D. J. Posselt, 2018: Orographic precipitation response to microphysical parameter perturbations for idealized moist nearly neutral flow. J. Atmos. Sci., 75, 1933-1953, https://doi.org/10.1175/JASD-17-0389.1.

Morris, M., 1991: Factorial sampling plans for preliminary computational experiments. Technometrics, 33, 161-174, https:// doi.org/10.1080/00401706.1991.10484804.

Morrison, H., and J. A. Milbrandt, 2015: Parameterization of cloud microphysics based on the prediction of bulk ice particle properties. Part I: Scheme description and idealized tests. J. Atmos. Sci., 72, 287-311, https://doi.org/10.1175/ JAS-D-14-0065.1.

Muller, C. J., L. E. Back, P. A. O'Gorman, and K. A. Emanuel, 2009: A model for the relationship between tropical precipitation and column water vapor. Geophys. Res. Lett., 36, L16804, https://doi.org/10.1029/2009GL039667.

Neelin, J. D., O. Peters, and K. Hales, 2009: The transition to strong convection. J. Atmos. Sci., 66, 2367-2384, https://doi.org/ 10.1175/2009JAS2962.1.

Pereira de Oliveira, F., and M. D. Oyama, 2015: Antecedent atmospheric conditions related to squall-line initiation over the northern coast of Brazil in July. Wea. Forecasting, 30, 12541264, https://doi.org/10.1175/WAF-D-14-00120.1.

Petch, J. C., and M. E. B. Gray, 2001: Sensitivity studies using a cloud-resolving model simulation of the tropical west Pacific. Quart. J. Roy. Meteor. Soc., 127, 2287-2306, https://doi.org/ 10.1002/qj.49712757705.

Posselt, D. J., 2016: A Bayesian examination of deep convective squall line sensitivity to changes in cloud microphysical parameters. J. Atmos. Sci., 73, 637-665, https://doi.org/10.1175/ JAS-D-15-0159.1.

- and T. Vukicevic, 2010: Robust characterization of model physics uncertainty for simulations of deep moist convection. Mon. Wea. Rev., 138, 1513-1535, https://doi.org/10.1175/ 2009MWR3094.1.

_ _ and C. H. Bishop, 2012: Nonlinear parameter estimation: Comparison of an ensemble Kalman smoother with a Markov chain Monte Carlo algorithm. Mon. Wea. Rev., 140, 19571974, https://doi.org/10.1175/MWR-D-11-00242.1.

— D. Hodyss, and C. H. Bishop, 2014: Errors in ensemble Kalman smoother estimates of cloud microphysical parameters. Mon. Wea. Rev., 142, 1631-1654, https://doi.org/10.1175/ MWR-D-13-00290.1.

$\longrightarrow$, X. Li, S. A. Tushaus, and J. R. Mecikalski, 2015: Assimilation of dual-polarization radar observations in mixed- and icephase regions of convective storms: Information content and forward model errors. Mon. Wea. Rev., 143, 2611-2636, https:// doi.org/10.1175/MWR-D-14-00347.1.

Raymond, D. J., and S. L. Sessions, 2007: Evolution of convection during tropical cyclogenesis. Geophys. Res. Lett., 34, L06811, https://doi.org/10.1029/2006GL028607.

Rickenbach, T. M., R. N. Ferreira, J. B. Halverson, D. L. Herdies, and M. A. F. Silva Dias, 2002: Modulation of convection in the southwestern Amazon basin by extratropical stationary fronts. J. Geophys. Res., 107, 8040, https://doi.org/10.1029/ 2000JD000263.

Rienecker, M. M., and Coauthors, 2008: The GEOS-5 data assimilation system-Documentation of versions 5.0.1 and 5.1.0, and 5.2.0. NASA Tech. Rep. NASA/TM-2008-104606, Vol. 27, $92 \mathrm{pp}$.

Rotunno, R., J. B. Klemp, and M. L. Weisman, 1988: A theory for strong, long-lived squall lines. J. Atmos. Sci., 45, 463-485, https://doi.org/10.1175/1520-0469(1988)045<0463:ATFSLL> 2.0.CO;2.

Roy, S. S., R. K. Datta, R. C. Bhatia, and A. K. Sharma, 2005: Drop-size distributions of tropical rain over south India. Geofizika, 22, 105-130.

Rutledge, S. A., and P. V. Hobbs, 1984: The mesoscale and microscale structure and organization of clouds and precipitation in midlatitude cyclones. XII: A diagnostic modeling study of precipitation development in narrow cold-frontal rainbands. J. Atmos. Sci., 41, 2949-2972, https://doi.org/10.1175/15200469(1984)041<2949:TMAMSA > 2.0.CO;2. 
Saleeby, S. M., and W. R. Cotton, 2004: A large-droplet mode and prognostic number concentration of cloud droplets in the Colorado State University Regional Atmospheric Modeling System (RAMS). Part I: Module descriptions and supercell test simulations. J. Appl. Meteor., 43, 182-195, https://doi.org/ 10.1175/1520-0450(2004)043<0182:ALMAPN>2.0.CO;2.

Schiro, K. A., J. D. Neelin, D. K. Adams, and B. R. Lintner, 2016: Deep convection and column water vapor over tropical land versus tropical ocean: A comparison between the Amazon and the tropical western Pacific. J. Atmos. Sci., 73, 4043-4063, https://doi.org/10.1175/JAS-D-16-0119.1.

Sessions, S. L., M. J. Herman, and S. Sentić, 2015: Convective response to changes in the thermodynamic environment in idealized weak temperature gradient simulations. J. Adv. Model. Earth Syst., 7, 712-738, https://doi.org/10.1002/2015MS000446.

Sherwood, S. C., 2010: Direct vs indirect effects of tropospheric humidity changes on the hydrologic cycle. Environ. Res. Lett., 5, 025206, https://doi.org/10.1088/1748-9326/5/2/025206.

- , R. Roca, T. M. Weckwerth, and N. G. Andronova, 2010: Tropospheric water vapor, convection, and climate. Rev. Geophys., 48, RG2001, https://doi.org/10.1029/2009RG000301.

Silva Dias, M. A. F., and Coauthors, 2002: Cloud and rain processes in a biosphere-atmosphere interaction context in the Amazon region. J. Geophys. Res., 107, 8072, https://doi.org/10.1029/ 2001JD000335.

Simpson, J., and W.-K. Tao, 1993: The Goddard Cumulus Ensemble model. Part II: Applications for studying cloud precipitating processes and for NASA TRMM. Terr. Atmos. Oceanic Sci., 4, 73-116.

Stevens, B., 2005: Atmospheric moist convection. Annu. Rev. Earth Planet. Sci., 33, 605-643, https://doi.org/10.1146/ annurev.earth.33.092203.122658.

_ , H. Brogniez, C. Kiemle, J.-L. Lacour, C. Crevoisier, and J. Kiliani, 2017: Structure and dynamical influence of water vapor in the lower tropical troposphere. Surv. Geophys., $\mathbf{3 8}$, 1371-1397, https://doi.org/10.1007/s10712-017-9420-8.

Takemi, T., 2015: Relationship between cumulus activity and environmental moisture during the CINDY2011/DYNAMO field experiment as revealed from convection-resolving simulations. J. Meteor. Soc. Japan, 93A, 41-58, https://doi.org/ 10.2151/jmsj.2015-035.

Tang, Y., H. W. Lean, and J. Bornemann, 2013: The benefits of the Met Office variable resolution NWP model for forecasting convection. Meteor. Appl., 20, 417-426, https://doi.org/10.1002/met.1300.

Tao, W.-K., 2007: Cloud resolving modeling. J. Meteor. Soc. Japan, 85B, 305-330, https://doi.org/10.2151/jmsj.85B.305.

_ Part I: Model description. Terr. Atmos. Oceanic Sci., 4, 35-72, https://doi.org/10.3319/TAO.1993.4.1.35(A).

_ J. R. Scala, B. S. Ferrier, and J. Simpson, 1995: The effect of melting processes on the development of a tropical and a midlatitude squall line. J. Atmos. Sci., 52, 1934-1948, https:// doi.org/10.1175/1520-0469(1995)052<1934:TEOMPO >2.0.CO;2.

—_, and Coauthors, 2003: Microphysics, radiation, and surface processes in the Goddard Cumulus Ensemble (GCE) model. Meteor. Atmos. Phys., 82, 97-137, https://doi.org/10.1007/ s00703-001-0594-7.

— , and Coauthors, 2014: The Goddard Cumulus Ensemble (GCE) model: Improvements and applications for studying precipitation processes. Atmos. Res., 143, 392-242, https:// doi.org/10.1016/j.atmosres.2014.03.005.

Tobin, I., S. Bony, and R. Roca, 2012: Observational evidence for relationships between the degree of aggregation of deep convection, water vapor, surface fluxes, and radiation. J. Climate, 25, 6885-6904, https://doi.org/10.1175/JCLI-D-11-00258.1.

Tokay, A., and D. A. Short, 1996: Evidence from tropical raindrop spectra of the origin of rain from stratiform versus convective clouds. J. Appl. Meteor., 35, 355-371, https://doi.org/10.1175/ 1520-0450(1996)035<0355:EFTRSO > 2.0.CO;2.

Tong, M., and M. Xue, 2008: Simultaneous estimation of microphysical parameters and atmospheric state with simulated radar data and ensemble square root Kalman filter. Part I: Sensitivity analysis and parameter identifiability. Mon. Wea. Rev., 136, 1630-1648, https://doi.org/10.1175/2007MWR2070.1.

Tsai, W.-M., and C.-M. Wu, 2017: The environment of aggregated deep convection. J. Adv. Model. Earth Syst., 9, 2061-2078, https://doi.org/10.1002/2017MS000967.

Tulich, S. N., and B. E. Mapes, 2010: Transient environmental sensitivities of explicitly simulated tropical convection. J. Atmos. Sci., 67, 923-940, https://doi.org/10.1175/2009JAS3277.1.

van den Heever, S. C., and W. R. Cotton, 2004: The impact of hail size on simulated supercell storms. J. Atmos. Sci., 61, 1596-1609, https://doi.org/10.1175/1520-0469(2004)061<1596: $\mathrm{TIOHSO}>2.0 . \mathrm{CO} ; 2$.

G. G. Carrio, W. R. Cotton, P. J. DeMott, and A. J. Prenni, 2006: Impacts of nucleating aerosol on Florida storms. Part I: Mesoscale simulations. J. Atmos. Sci., 63, 1752-1775, https:// doi.org/10.1175/JAS3713.1.

Virman, M., M. Bister, V. A. Sinclair, H. Järvinen, and J. Räisänen, 2018: A new mechanism for the dependence of tropical convection on free-tropospheric humidity. Geophys. Res. Lett., 45, 2516-2523, https://doi.org/10.1002/2018GL077032.

Walko, R. L., W. R. Cotton, M. P. Meyers, and J. Y. Harrington, 1995: New RAMS cloud microphysics parameterization. Part I: The single-moment scheme. Atmos. Res., 38, 29-62, https:// doi.org/10.1016/0169-8095(94)00087-T.

Wandishin, M. S., D. J. Stensrud, S. L. Mullen, and L. J. Wicker, 2008: On the predictability of mesoscale convective systems: Two-dimensional simulations. Wea. Forecasting, 23, 773-785, https://doi.org/10.1175/2008WAF2007057.1.

Wang, H., J. Sun, X. Zhang, X.-Y. Huang, and T. D. Auligne, 2013: Radar data assimilation with WRF 4D-Var. Part I: System development and preliminary testing. Mon. Wea. Rev., 141, 2224-2244, https://doi.org/10.1175/MWR-D-12-00168.1.

Wang, S., and A. H. Sobel, 2017: Factors controlling rain on small tropical islands: Diurnal cycle, large-scale wind speed, and topography. J. Atmos. Sci., 74, 3515-3532, https://doi.org/ 10.1175/JAS-D-16-0344.1.

Weisman, M. L., and J. B. Klemp, 1982: The dependence of numerically simulated convective storms on vertical wind shear and buoyancy. Mon. Wea. Rev., 110, 504-520, https://doi.org/ 10.1175/1520-0493(1982)110<0504:TDONSC >2.0.CO;2.

Wu, X., W. D. Hall, W. W. Grabowski, M. W. Moncrieff, W. D. Collins, and J. T. Kiehl, 1999: Long-term behavior of cloud systems in TOGA COARE and their interactions with radiative and surface processes. Part II: Effects of ice microphysics on cloud-radiation interaction. J. Atmos. Sci., 56, 3177-3195, https:// doi.org/10.1175/1520-0469(1999)056<3177:LTBOCS > 2.0.CO;2.

Yuan, J., 2016: Variability of oceanic deep convective system vertical structures observed by CloudSat in Indo-Pacific regions associated with the Madden-Julian oscillation. J. Geophys. Res. Atmos., 121, 10 761-10 785, https://doi.org/10.1002/2016JD025262.

Zeng, X., W.-K. Tao, S. Lang, A. Y. Hou, M. Zhang, and J. Simpson, 2008: On the sensitivity of atmospheric ensembles to cloud microphysics in long-term cloud-resolving model simulations. J. Meteor. Soc. Japan, 86, 45-65, https://doi.org/10.2151/jmsj.86A.45. 